\title{
Gas Flare Design Debottlenecking Using Pinch Analysis
}

\author{
Lawrence Leelabari Pemii, Kenneth Kekpugile Dagde, ThankGod Oweifa Goodhead
}

Department of Chemical/Petrochemical Engineering, Rivers State University, Nkpolu-Oroworukwo, Nigeria

Email: lawrence.1.pemii@gmail.com, dagde.kenneth@ust.edu.ng

How to cite this paper: Pemii, L.L., Dagde, K.K. and Goodhead, T.O. (2020) Gas Flare Design Debottlenecking Using Pinch Analysis. Advances in Chemical Engineering and Science, 10, 297-321.

https://doi.org/10.4236/aces.2020.104019

Received: May 30, 2020

Accepted: September 1, 2020

Published: September 4, 2020

Copyright $\odot 2020$ by author(s) and Scientific Research Publishing Inc. This work is licensed under the Creative Commons Attribution International License (CC BY 4.0).

http://creativecommons.org/licenses/by/4.0/

\begin{abstract}
Gas flaring is concerned with the combustion of lighter ends of hydrocarbon mostly produced in association with crude oil. Flare networks are designed to handle the gas volume required to be flared. Most times, this flare networks are in close proximity but still have independent flare stacks, increasing risk to environment and cost on infrastructures. There is a need to integrate the flare networks in facilities within same area and through the application of Pinch Analysis concept, the resultant flare network can be optimized to give a system having optimal tail and header pipe sizes that will reduce cost and impact on environment. In the light of the foregoing, the concept of pinch analysis was used in debottlenecking integrated gas flare networks from a flow station and a refinery in close proximity. Both flare networks were integrated and the resultant gas flare network was optimized to obtain the optimum pipe header and tail pipe sizes with the capacity to withstand the inventory from both facilities and satisfy the set constraints such as Mach number, noise, $\mathrm{RhoV}^{2}$ and backpressure. Mach number was set at 0.7 for tail pipes and 0.5 for header pipes, noise limit was not to exceed $80 \mathrm{~dB}$ upstream and $115 \mathrm{~dB}$ downstream the sources, $\mathrm{RhoV}^{2}$ was limited to $6000 \mathrm{~kg} / \mathrm{m} / \mathrm{s}^{2}$ and the back pressure requirement was source dependent respectively. The fire case scenario was considered, as it is the worst-case scenario in the studies. When pinch analysis was applied in debottlenecking the combined gas flare network, it gave smaller tail and header pipe sizes which is more economical. A 20\% decrease in pipe sizes was recorded at the end of the study.
\end{abstract}

\section{Keywords}

Gas Flaring, Pinch Analysis, Debottlenecking, Aspen FlareNet, Optimization, Header Pipe, Tail Pipe

\section{Introduction}

Gas flaring has to do with the combustion of associated, unwanted or excess 
gases and liquids produced during normal operation or sudden over-pressuring operation in industrial processes, example, oil \& gas extraction, refineries, chemical plants, coal industry, etc [1]. A Flare Gases Recovery System research posited that; if the Flare Gases Recovery Systems (FGRS) is used, then wasted energy can be recovered and emission of greenhouse gases prevented [2]. With increasing awareness of the environmental impact and the ratification of the Kyoto protocol by most of the member countries, it is expected that gas flaring will not be allowed in the near future [2]. The launch of Nigeria Gas Flare Commercialization Programme (NGFCP) by the Federal Government of Nigeria lends credence to the fact that Nigeria too is determined to cut gas flaring activities, though, there are existing flare systems exempted from the program for the mean time due to peculiarities of such facilities [3]. In 2015 there were 39 companies directly involved in oil and gas production in Nigeria, producing natural gas from 189 fields with daily Associated Gas (AG) production of 4.74 bscf/d and Non-associated Gas (NAG) production of nearly $3.46 \mathrm{bscf} / \mathrm{d}$ [4]. There is a high probability that even when the flared gas is utilized for power supply, there will still exist operational flare systems to carter for system upsets in processing or production plants and other oil and gas facilities. Thus, the need to research the viability of applying the concept of pinch analysis in debottlenecking integrated gas flare networks. According to [5], Pinch technology is concerned with the optimization of energy utilized in the Process industries. It is based on thermodynamic method, to develop minimum energy levels required in heat exchanger networks, using the first and second laws of thermodynamics to analyze chemical process and utility systems. The prime objective of pinch technology is to achieve financial savings by better process heat integration (maximizing process-to-process heat recovery and reducing the external utility loads) [6]. It also implies that a set point is defined before a design is carried out. Pinch started in the petrochemical sector and is now being utilized to solve a variety of problems in mainstream chemical engineering [7]. Early emphasis on energy conservation led to the misconception that conservation is the main area of application of pinch technology. The technology, when applied with imagination, can affect reactor design, separator design, and the overall process optimization in any plant [8]. It has been applied to processing problems that go far beyond energy conservation. It has been employed to solve problems as diverse as improving effluent quality, reducing emissions, increasing product yield, debottlenecking, increasing throughput, and improving the flexibility and safety of the processes [9].

A study on Flare Radiation Mitigation Analysis of Onshore Oil \& Gas Production \& Refining Facility for a Low-Cost De-Bottlenecking using Computer Aided Techniques by [10] resulted in a low-cost de-bottlenecking in existing facilities to enhance its current capacity. A flare system consists of different relief units that handle depressurization for the different processes taking place on the platform, to ensure safety of life and property on it [11]. Unifying principles for 
Pinch approaches to resource conservation have been noted by [12], while [13] have noted the common underlying principles for general allocation problems. It was noted that the Pinch Method can be viewed as a special case of a multiple-component Linear Programing (LP) problem.

Pinch Analysis had been proven to be effective in optimization processes. Multi-dimensional pinch analysis promises to be an effective tool for sustainability analysis in the years to come; most importantly in the developing world where social well-being and economic development are priorities in the years ahead, and they ought to be attained by a simultaneous truncation of the environmental footprint, in other words, an optimization of resource utilization as well as adverse environmental impacts. In other words, the focus ought to be on sustainable production (efficiency) and consumption (sufficiency) [14].

Risk management in the process industries had been analyzed using the pinch methodology as established [15]. This technique enables Pinch Analysis philosophy to be applied to the problem of allocating resources to mitigate risks in industrial processes. The graphical Pinch approach used here facilitates decision-making, while remaining consistent with conventional data displays used in risk analysis. A case study based on the infamous Bhopal incident has been solved to illustrate this approach. The solution determined is identical to that reported in literature using 0-1 programming models. This work contributes a novel approach to risk management which can be used as an alternative or supplement to mathematical programming. One of the challenges to oil and gas facilities is the proper management of excess gas either from production or as a result of processing activities. Most facilities have multiple flare stacks in close proximity while they can actually be combined and optimized to limit impact on environment and safe cost. In this research, Pinch Analysis is applied in debottlenecking a combined gas flare networks from Egam Flow station and Onage refinery to get optimum tailpipes, header pipes, and flare stack pipe sizes required for efficient handling of fluid volume and necessary upsets. In this paper, an integrated flare network had been debottlenecked using the concept of Pinch Analysis to safe cost and enhance safer environment.

\section{Materials and Methods}

The following theoretical basis for thermo-hydraulic modeling of flow in flare systems are considered in this work. The continuity equations such as, mass balance, energy balance, and momentum balance equations were developed to form the model equations of the system.

\subsection{Design Assumptions}

The following assumptions were made of the flow regimes for the development of the design models:

1) A steady state incompressible flow where density is constant. This largely simplified the conservation laws, as compressibility effects were neglected. 
2) A compressible flow(flow of gas or vapor). Fluid properties such as density and volume are a function of temperature and pressure. This strongly influences the flow behavior.

3) Adiabatic flow where there is no heat transfer, $\mathrm{qH}=0$.

4) Isothermal flow where temperature is said to be approximately constant. In this case the internal energy and enthalpy remain constant.

5) One dimensional flow in the axial direction is assumed.

Figure 1 shows a schematic of flow chart of flare network indicating the feeder flare header, knock out drum, flare stack, the liquid and gaseous outlet. Figure 2 depicts the map of Nigeria indicating the data of gas flared from 2015 to 2019 .

\subsection{Material Balance}

The general conservation equations for one dimensional flow is written as follows:

$$
\begin{aligned}
& \frac{\text { Rate of mass flow }}{\text { time }} \\
& -\frac{\text { Rate of accumulation ofmass }}{\text { time }}+\frac{\text { Rate mass inflow to controlled volume }}{\text { time }} \\
\text { Rate of mass flow out of controlled volume } & (1)
\end{aligned}
$$

Thus, Equation (1) can be written mathematically as:

$$
\frac{\mathrm{d} M_{s}}{\mathrm{~d} t}=\frac{\mathrm{d} M_{c v}}{\mathrm{~d} t}+\frac{\mathrm{d} M_{c v}^{\text {out }}}{\mathrm{d} t}-\frac{\mathrm{d} M_{c v}^{\text {in }}}{\mathrm{d} t}=0
$$

where; $M_{s}$ is the mass flowrate of the system $(\mathrm{kg} / \mathrm{hr}), S$ is the system, $M_{c r}$ represents the mass flowrate within the controlled volume $(\mathrm{kg} / \mathrm{hr})$, and $t$ is the time(s).

Since the control volume is fixed, the accumulation of mass within the control volume is:

$$
\frac{\mathrm{d} M_{c v}}{\mathrm{~d} t}=\frac{V \partial \rho_{c v}}{\partial t}
$$

where $\rho_{c v}$ is the average density within controlled volume which varies with time, $V$ is the Controlled volume. But:

$$
\begin{aligned}
& \frac{\mathrm{d} M_{c v}^{\text {out }}}{\mathrm{d} t}=\rho_{2} A_{2} u_{2} \\
& \frac{\mathrm{d} M_{c v}^{\text {in }}}{\mathrm{d} t}=\rho_{1} A_{1} u_{1}
\end{aligned}
$$

Therefore, for transient flow

$$
\rho_{1} A_{1} u_{1}-\rho_{2} A_{2} u_{2}=\frac{V \partial \rho_{c v}}{\partial t}
$$

For steady state flow, $\frac{V \partial \rho_{c v}}{\partial t}=0$ i.e. 


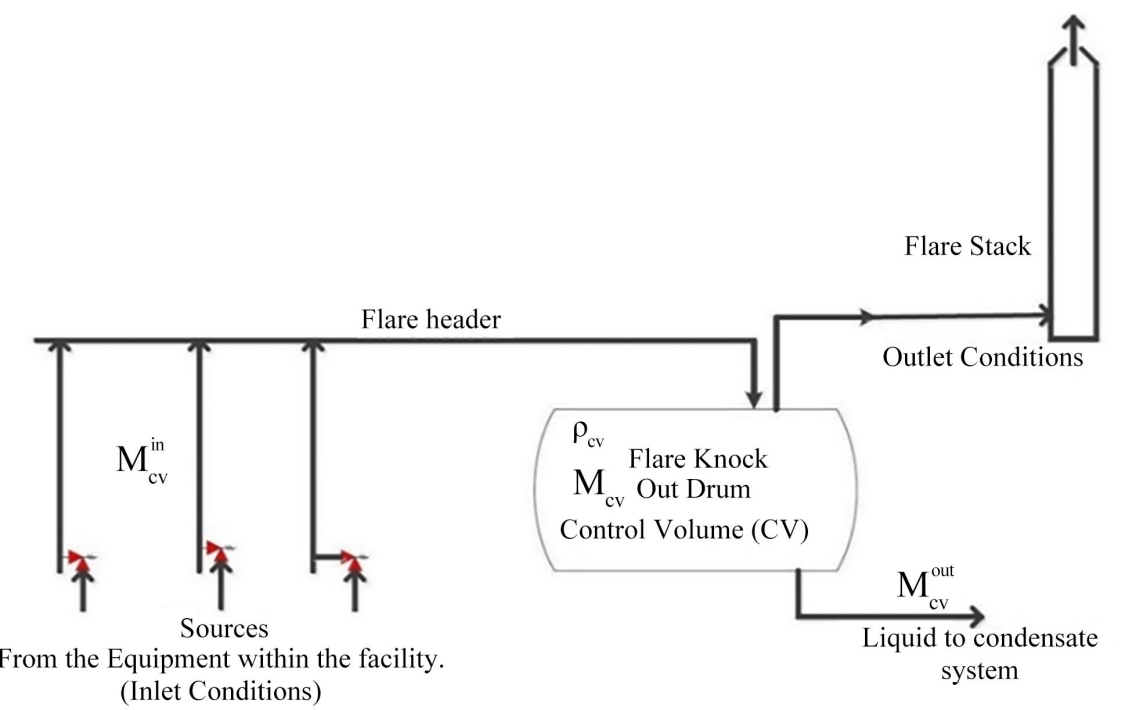

Figure 1. Flare network schematics.

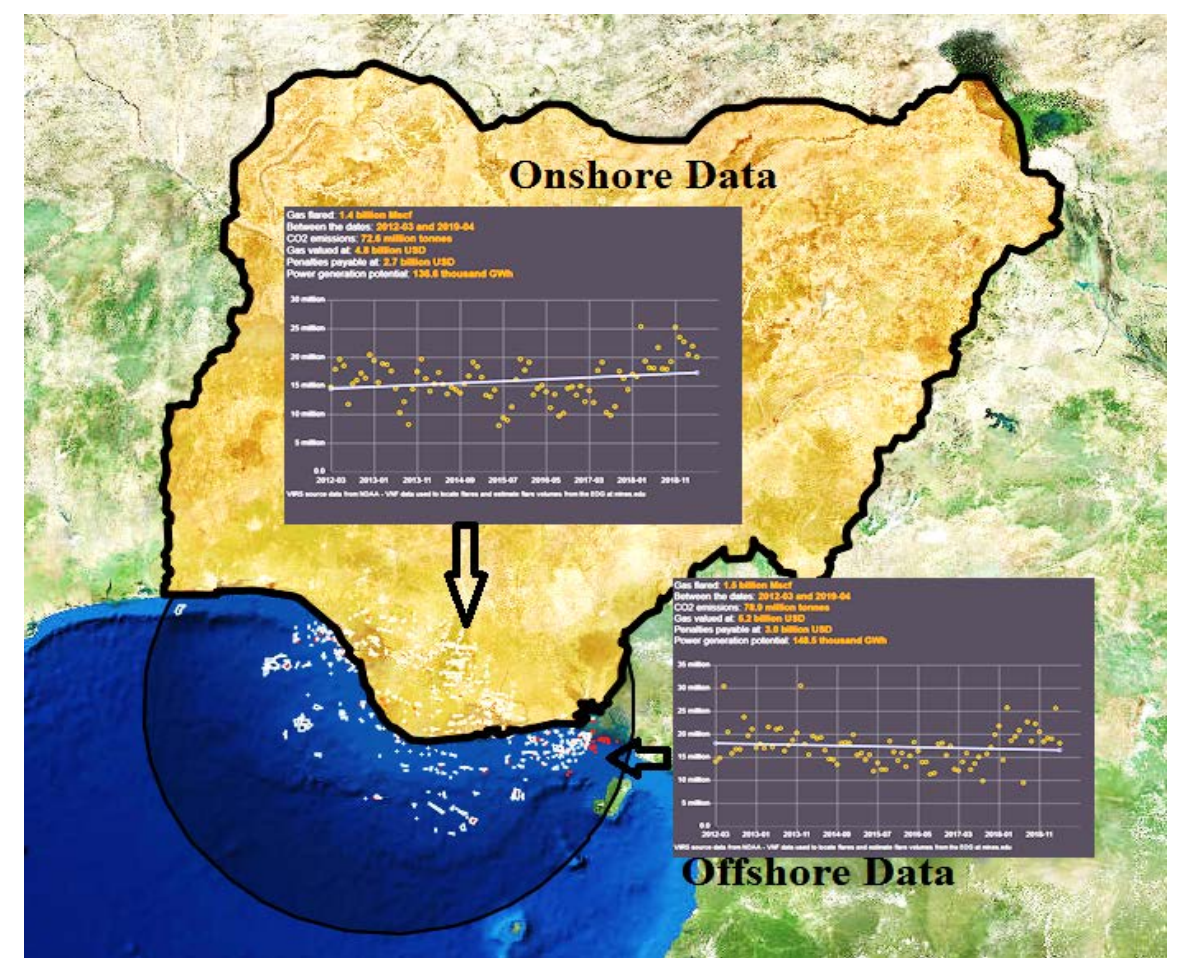

Figure 2. Gas flare data in nigeria (2012-2019) [16].

$$
\begin{gathered}
\rho_{1} A_{1} u_{1}-\rho_{2} A_{2} u_{2}=0 \\
\rho_{1} A_{1} u_{1}=\rho_{2} A_{2} u_{2}=\rho A u
\end{gathered}
$$

where, $m$ is the mass, $\rho$ the fluid density, $A$ the cross-sectional area, $u$ the flow velocity and Mass flow rate, $m$ is $\rho A u=$ constant

\subsection{Energy Balance}

Recalling theenergy continuity equation: 


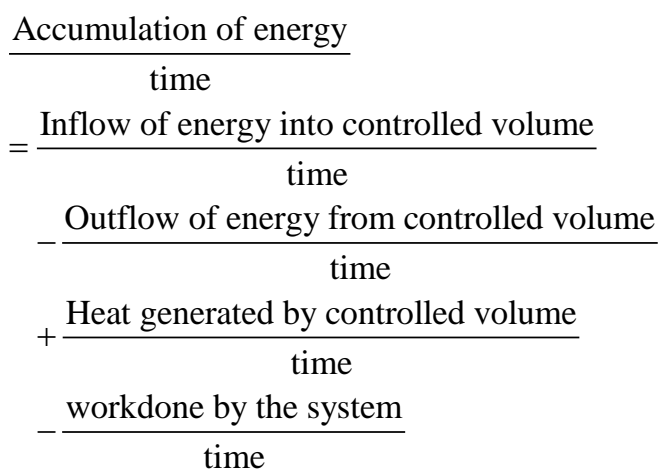

Thus, the above terms in Equation (9) can be written mathematically as:

$$
\begin{aligned}
\frac{\mathrm{d} E}{\mathrm{~d} t}= & \sum_{i=\text { inlets }} m_{i}\left\{e+\frac{v^{2}}{2}+g z+\frac{P}{\rho}\right\}_{i} \\
& -\sum_{i=\text { outlets }} m_{i}\left\{e+\frac{v^{2}}{2}+g z+\frac{P}{\rho}\right\}_{i}+\frac{\mathrm{d} q}{\mathrm{~d} t}-\frac{\mathrm{d} W}{\mathrm{~d} t}
\end{aligned}
$$

where, $\frac{\mathrm{d} E}{\mathrm{~d} t}$ is the accumulation of energy within the system.

For steady state flow accumulation is always equal to zero, therefore the energy balance equation simplifies to the form:

$$
\begin{aligned}
0= & \sum_{i=\text { inlets }} m_{i}\left\{e+\frac{v^{2}}{2}+g z+\frac{P}{\rho}\right\}_{i} \\
& -\sum_{i=\text { outlets }} m_{i}\left\{e+\frac{v^{2}}{2}+g z+\frac{P}{\rho}\right\}_{i}+\frac{\mathrm{d} q}{\mathrm{~d} t}-\frac{\mathrm{d} W}{\mathrm{~d} t}
\end{aligned}
$$

where, $e$ is specific internal energy, $P$ is the pressure, $g$ the gravitational constant, $z$ the elevation, $q$ the heat and $w$ is the work done.

For gases, $e+P l \rho=h$, the specific enthalpy. Thus, the Equation (10) may now be written as:

$$
\frac{\mathrm{d} E}{\mathrm{~d} t}=\sum_{i=\text { inlets }} m_{i}\left\{h+\frac{v^{2}}{2}+g z\right\}_{i}-\sum_{i=\text { outlets }} m_{i}\left\{h+\frac{v^{2}}{2}+g z\right\}_{i}+\frac{\mathrm{d} q}{\mathrm{~d} t}-\frac{\mathrm{d} W}{\mathrm{~d} t}
$$

\subsection{Momentum Balance}

The general momentum balance equation:

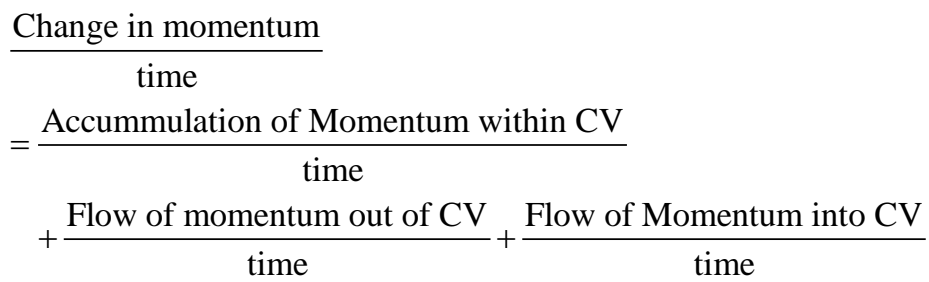

From Newton's second law:

$$
\sum F=\frac{\mathrm{d}(m u)_{s}}{\mathrm{~d} t}=\frac{\mathrm{d}(m u)_{c v}}{\mathrm{~d} t}+\frac{\mathrm{d}(m u)_{c v}^{\text {out }}}{\mathrm{d} t}-\frac{\mathrm{d}(m u)_{c v}^{\text {in }}}{\mathrm{d} t}
$$


For unsteady state flow condition there would be accumulation of momentum $\left(\frac{\mathrm{d}(m u)_{c v}}{\mathrm{~d} t}\right)$ within the control volume, so:

$$
\sum F=\frac{\mathrm{d}(m u)_{c v}}{\mathrm{~d} t}+\frac{\mathrm{d}(m u)_{c v}^{\text {out }}}{\mathrm{d} t}-\frac{\mathrm{d}(m u)_{c v}^{\text {in }}}{\mathrm{d} t}
$$

For steady state flow condition there is no accumulation of momentum within the control volume, $\frac{\mathrm{d}(m u)_{c v}}{\mathrm{~d} t}=0$, so:

$$
\sum F=\frac{\mathrm{d}(m u)_{c v}^{\text {out }}}{\mathrm{d} t}-\frac{\mathrm{d}(m u)_{c v}^{\text {in }}}{\mathrm{d} t}
$$

But,

$$
\frac{\mathrm{d}(m u)_{i}}{\mathrm{~d} t}=\frac{\mathrm{d} m_{i}}{\mathrm{~d} t} u_{i}=m u
$$

Thus,

$$
\sum F=(m u)^{\text {out }}-(m u)^{\text {in }}
$$

Equations (8), (12) and (18) are the model equations for the flare system and has no limit in their application to similar studies.

\subsection{Design Basis/Input Parameters}

The basis of design for this research has the data presented in Tables 1-3. Pinch Analysis was carried out on the flare network to determine the optimum tailpipe, sub header, main header and flare stack pipe sizes (Pinch Point) required for optimal operation of the flare system. Input parameters employed were; fluid composition, pipe type with size (Carbon Steel or Stainless Steel, pipe inner diameter and roughness) and geometry (length and elevation). Pressure and Temperature upstream the relief and blow-down valves, and relieving rates (mass flow rate). Ambient conditions were also specified, with atmospheric conditions downstream the flare tip. FlareNet estimated the system variables (temperature and pressure in the pipe system and reports results for inlet end (upstream) and outlet end (downstream) of each pipe segment/section, and line sizes [diameters]), based on input data and system constraints. The pressure and temperature (corresponding to inlet temperature and heat balance along pipe system) was first estimated starting from the flare tip, backwards to upstream the tailpipes; then the lines were sized in the opposite direction from upstream tailpipes to the flare tip, based on estimated flow parameters (This was an iterative process).

\subsection{Design Input Data}

The data shown in Table 1 are the general input data and defined constraints for the simulation of the system.

The following data were input process parameters for each of the valves within the defined sources. The sources were the Pressure Safety and Pressure Con- 
trol Valves on each of the vessels and processes defined by the source names.

The fluid composition of each source is shown on Table 3.

Table 1. Design parameters (plant data) [17].

\begin{tabular}{|c|c|c|c|}
\hline S/No. & Parameter & Value & Unit \\
\hline 1 & Pipe length Multiplier & 1.5 & \\
\hline 2 & Valve type & Conventional & \\
\hline 3 & Flare tip diameter & 406.4 & $\mathrm{Mm}$ \\
\hline 4 & Knock out drum size & 2200 & $\mathrm{Mm}$ \\
\hline 5 & Vapour velocity & 18.29 & $\mathrm{~m} / \mathrm{s}$ \\
\hline 6 & Liquid Velocity & 4.57 & $\mathrm{~m} / \mathrm{s}$ \\
\hline 7 & $\mathrm{C}_{7}^{+}$Normal boiling point & 110 & ${ }^{\circ} \mathrm{C}$ \\
\hline 8 & Mach No & $0.7 \& 0.5$ for tail \& header pipes & \\
\hline 9 & Noise level & $85 / 115$ & $\mathrm{Db}$ \\
\hline 10 & $\mathrm{RhoV}^{2}$ & 6000 & $\mathrm{~kg} / \mathrm{ms}^{-2}$ \\
\hline 11 & Pipe schedule & 40 & \\
\hline
\end{tabular}

Table 2. Source data (plant data) [17].

\begin{tabular}{|c|c|c|c|c|c|c|}
\hline $\begin{array}{l}\text { Source } \\
\text { Name }\end{array}$ & Valve & $\begin{array}{c}\text { Mass Florwate } \\
(\mathrm{kg} / \mathrm{hr})\end{array}$ & $\begin{array}{l}\text { Inlet Pressure } \\
\text { (bar abs) }\end{array}$ & $\begin{array}{l}\text { Inlet Temp } \\
\left({ }^{\circ} \mathrm{C}\right)\end{array}$ & $\begin{array}{c}\text { MAWP } \\
\text { (bar abs) }\end{array}$ & $\begin{array}{c}\text { Orifice } \\
\text { Designation }\end{array}$ \\
\hline Surge Vessel 1 & PSV & 200 & - & 343.30 & 2.7570 & Size \\
\hline Surge Vessel 2 & PSV & 200 & - & 343.30 & 2.7570 & Size \\
\hline \multirow{2}{*}{ XXHP } & PCV & 4392 & 47 & 37.78 & - & \\
\hline & PSV & 4400 & - & 90 & 97.9056 & Size \\
\hline \multirow{2}{*}{ XHP } & PCV & 5000 & 25 & 90 & - & \\
\hline & PSV & 2420 & - & 70 & 34.48 & Size \\
\hline \multirow{2}{*}{ HP1 } & PCV & 1200 & 13.01 & 93.33 & - & \\
\hline & PSV & 1200 & - & 93.33 & 15.8671 & Size \\
\hline \multirow{2}{*}{ HP2 } & PCV & 4050 & 12 & 93.33 & - & \\
\hline & PSV & 1050 & - & 93.33 & 15.8571 & Size \\
\hline \multirow{2}{*}{ LP1 } & PCV & 450 & 10 & 93.33 & - & \\
\hline & PSV & 500 & - & 93.33 & 15.8571 & Size \\
\hline \multirow{2}{*}{ LP2 } & PCV & 450 & 10 & 93.33 & - & \\
\hline & PSV & 500 & - & 93.33 & 15.8571 & Size \\
\hline FG scrubber & PSV & 1720 & 10.06 & 93.33 & 15.8571 & Size \\
\hline FG Heater & PSV & 1720 & 6.36 & 93.33 & 15.8571 & Size \\
\hline Relief Valve 3 & PSV & 1720 & 28 & 93.33 & 15.8571 & Size \\
\hline Slop tank & PSV & 111.3 & 10.06 & 93.33 & 15.8571 & Size \\
\hline
\end{tabular}


Table 3. Source compositions (plant data) [17].

\begin{tabular}{|c|c|c|c|c|c|c|c|c|c|c|}
\hline \multirow{2}{*}{ Component } & \multicolumn{10}{|c|}{ Composition in mole fraction } \\
\hline & XXHP & XHP & HP1 & HP2 & LP1 & LP2 & KO & SV1 & SV2 & OnagePSV \\
\hline Nitrogen & 0.006600 & 0.005000 & 0.004600 & 0.004600 & 0.003100 & 0.003100 & 0.004300 & 0.000600 & 0.000600 & 0.004300 \\
\hline $\mathrm{CO}_{2}$ & 0.058500 & 0.029003 & 0.029003 & 0.029003 & 0.027203 & 0.027203 & 0.025297 & 0.025100 & 0.025100 & 0.025297 \\
\hline $\mathrm{H}_{2} \mathrm{~S}$ & 0.000000 & 0.000000 & 0.000000 & 0.000000 & 0.000000 & 0.000000 & 0.000000 & 0.000000 & 0.000000 & 0.000000 \\
\hline Methane & 0.540100 & 0.723200 & 0.680569 & 0.689569 & 0.514451 & 0.514451 & 0.755424 & 0.223200 & 0.223200 & 0.755424 \\
\hline Ethane & 0.122900 & 0.097100 & 0.098510 & 0.098510 & 0.108711 & 0.108711 & 0.083492 & 0.129300 & 0.129300 & 0.083492 \\
\hline Propane & 0.142000 & 0.081200 & 0.095210 & 0.095210 & 0.160166 & 0.160116 & 0.072593 & 0.268600 & 0.268600 & 0.072593 \\
\hline i-Butane & 0.049200 & 0.023500 & 0.029103 & 0.029103 & 0.060906 & 0.060906 & 0.021198 & 0.112900 & 0.112900 & 0.021198 \\
\hline n-Butane & 0.045800 & 0.022500 & 0.029103 & 0.029103 & 0.064906 & 0.064906 & 0.020698 & 0.122600 & 0.122600 & 0.020698 \\
\hline i-Pentane & 0.014800 & 0.006900 & 0.009001 & 0.009001 & 0.021602 & 0.021602 & 0.006199 & 0.041900 & 0.041900 & 0.006199 \\
\hline n-Pentane & 0.011200 & 0.005300 & 0.006901 & 0.006901 & 0.016802 & 0.016802 & 0.004720 & 0.032500 & 0.032500 & 0.004720 \\
\hline n-Hexane & 0.006400 & 0.002100 & 0.002900 & 0.002900 & 0.002000 & 0.007001 & 0.002000 & 0.013600 & 0.013600 & 0.002000 \\
\hline n-Heptane & 0.000000 & 0.000100 & 0.000100 & 0.000100 & 0.000100 & 0.000100 & 0.000000 & 0.029500 & 0.000200 & 0.000000 \\
\hline $\mathrm{H}_{2} \mathrm{O}$ & 0.002200 & 0.003700 & 0.006001 & 0.006001 & 0.015102 & 0.015102 & 0.004100 & 0.000200 & 0.029500 & 0.004100 \\
\hline $\mathrm{C}_{7}^{+}$ & 0.000300 & 0.000000 & 0.000000 & 0.000000 & 0.000000 & 0.000000 & 0.000000 & 0.000000 & 0.000000 & 0.000000 \\
\hline
\end{tabular}

\subsection{Solution Techniques}

Aspen Flare Systems Analyzer (FlareNet) from Aspen Techis a steady state simulation tool specifically tailored for flare system design. It is used for design phase work such as line sizing, valve sizing; for simulating different relief scenarios, blow-down, debottlenecking, and other modifications. Building a model in FlareNet involves in-built materials commonly used for flare system design. FlareNet provides several options of traditional flow simulation models and correlations for pressure drop calculations, additional fittings loss calculation for bends and restrictions, tee pressure loss correlations, and equations of state, among others. Available pressure drop models include those for single phase gas flow and multi-phase flow such as; Isothermal flow, Adiabatic gas flow, Beggs \& Brills, Taitel \& Duckler, Lockhart Martinelli etc.; tee correlations such as: Miller's correlation, Gardel's correlation; equations of state include: compressible gas, SRK, Peng Robinson. FlareNet gives the opportunity to build a flare system model and simulate within the boundaries of accepted guidelines and standards (API, NORSOK, ISO), by specifying system constraints such as; allowable Mach within the different lines, from tailpipes to flare stack, noise, radiation, allowable back-pressure.

\section{Results and Discussion}

The results of the Aspen FlareNet simulation for Egam flow station and Onage refinery are presented in Figure 1. A combination of both flare networks was debottlenecked (optimized) to obtain the pinch point. The Pinch Point was the optimum pipe sizes obtained after debottlenecking the combined flare networks. A plot of the tail pipes versus the internal diameters indicated a $20 \%$ difference in the internal diameters of the tails pipes as a result of the application of the concept of pinch analysis. From Figure 1, line3 (xxHP tail pipe), the main header, relief hear and flare stack had the highest difference in diameters. The headers 
and flare stack are critical to the flare network design as they hold the entire inventory from all the sources in the network. A poorly designed flare headers and flare stack could lead to high back pressures, noise and vibrations in the system. Other tail pipes had slight differences in their internal diameters while the rest had approximately the same diameters when compared (Figure 3 below refers).

The criteria used for the simulation process was analyzed to show that the simulated result satisfied the constraint, a condition for measuring the accuracy of the outcome.

\subsection{Constraints}

In this paper four (4) constraints were considered: Backpressure requirement, Mach no, Noise and Rho $\mathrm{V}^{2}$ respectively. Results selected sources are as follows.

\subsubsection{Allowable Back Pressure}

Increase or decrease in Pressure Safety Valve (PSV) tail pipe or flare header size may decrease or increase backpressure to the PSV. A conventional spring-loaded PSV, Maximum Allowable Back Pressure (MABP) is typically limited to $10 \%$ of the PSV set pressure. A balanced bellow (or piston) type pressure relief valve, MABP is typically limited to $30 \%-50 \%$ of the PSV set pressure. For pilot operated PSV, MABP of more than $50 \%$ of the PSV set pressure was allowed (API Std 526). In this work, the conventional spring-loaded PSV was used, thus, an MABP limited to $10 \%$ of the PSV set pressure was the constraint. Each source within the combined and debottlenecked flare network were tested to ensure they satisfied the allowable back pressure requirement. The node pressure was required to be less than or equal to the allowable back pressure. The following Figures 4(a)-(f) show the back pressure requirement constraint for all the sources(nodes).

From Figure 4(a), the maximum back pressure for the source PSV on the Surge Vessel 1 was 1.176 bar, at the outlet of the flare tip, the least back pressure was recorded with a value 1.014 bar. The recorded backpressures were below the allowable back pressure, thus, the source results with respect to back pressure was proved satisfactory.

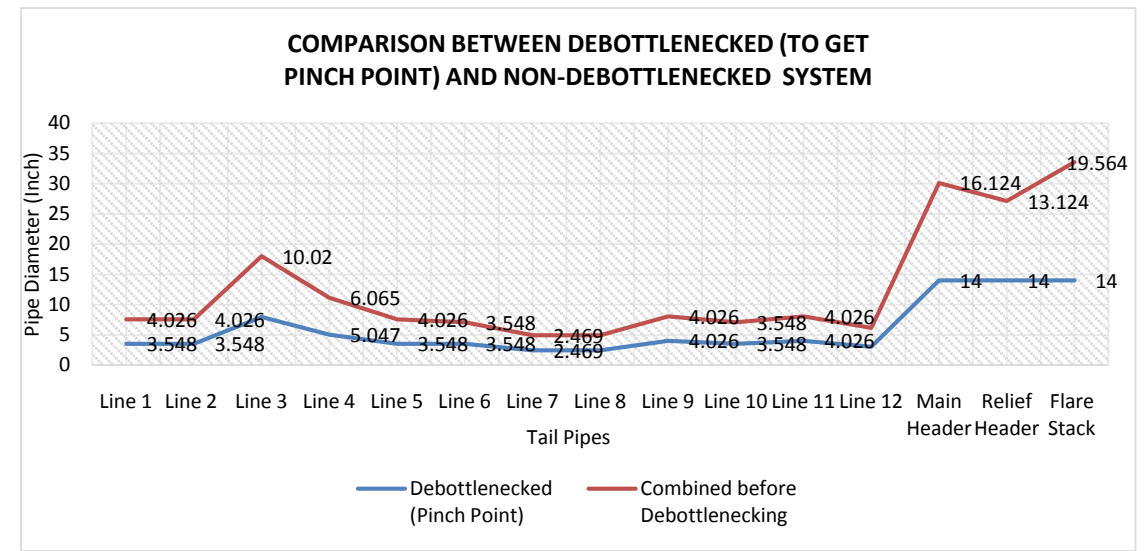

Figure 3. Comparison between debottlenecked and non-debottlenecked system. 
Extra extra High-Pressure separator, Pressure Safety Valve had a very high difference between the backpressure set point and the source backpressure. The source had 1.522 bar at the xxHP inlet and 1.030 bar at the outlet of the flare tip. The backpressure values were deemed okay with regard to the set constraint, thus, the values in Figure 4(b) are accepted.

Extra High Pressure (xHP) separator, Pressure Safety Valve fulfilled its backpressure concern as depicted in Figure 4(c). A value of 1.715 bar was the maximum backpressure value while 1.021 bar was recorded at the outlet of the flare tip. The backpressure limit was not exceeded; thus, the source result was deemed satisfactory in terms of backpressure.

The High Pressure 1 separator, Pressure Safety Valve (HP1 PSV), had a sharp decline in backpressure towards the outlet of the flare tip, 1.014 bar recorded at the flare tip and 2.359 bar at the source. The backpressure constraint was satisfactorily met as the backpressure regime of the source was within the required limit of the specified constraint.

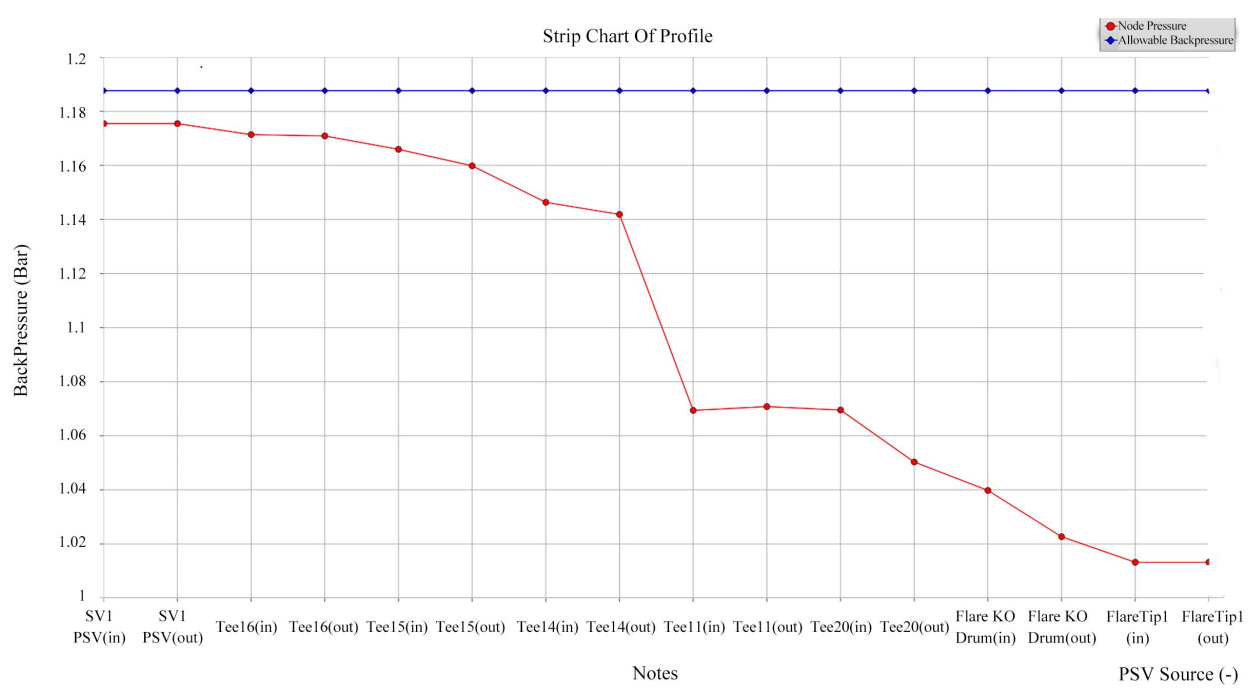

(a)

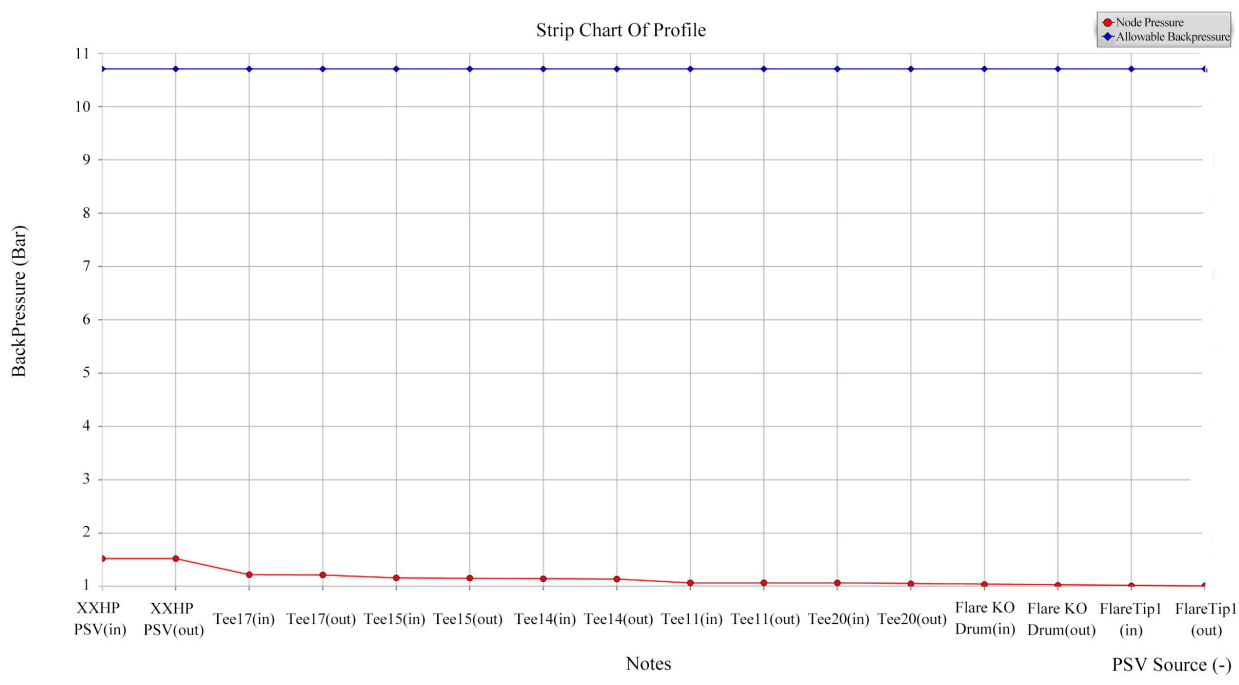

(b) 


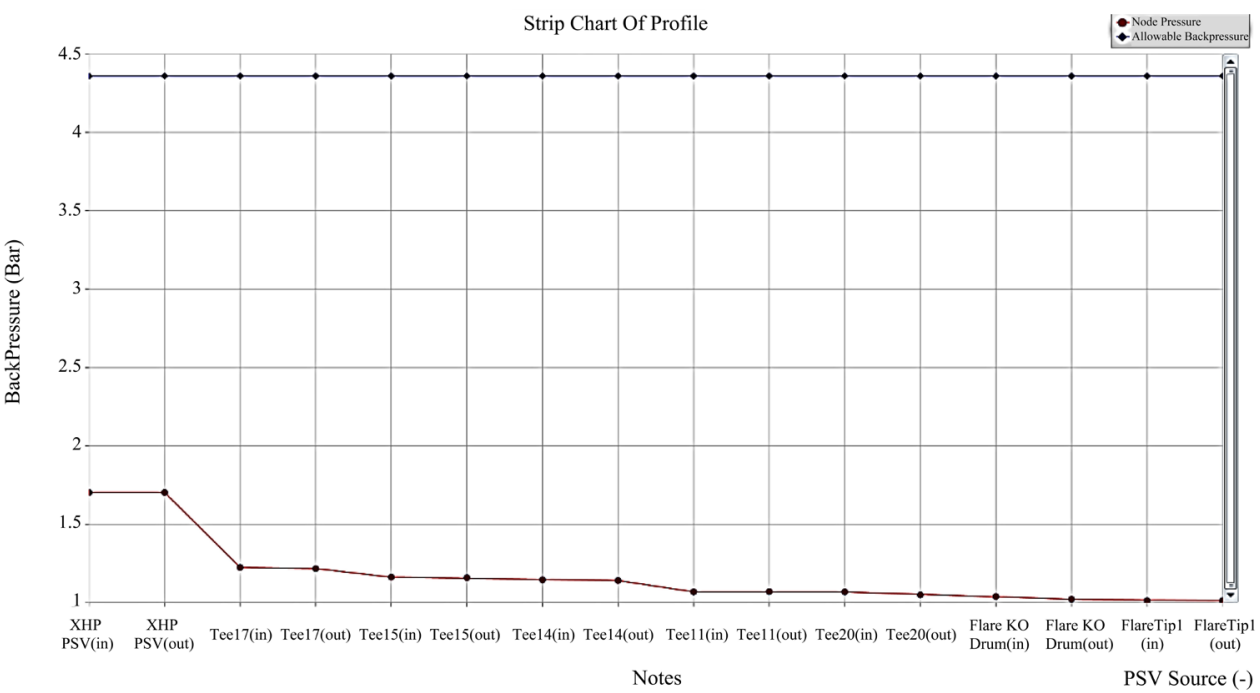

(c)

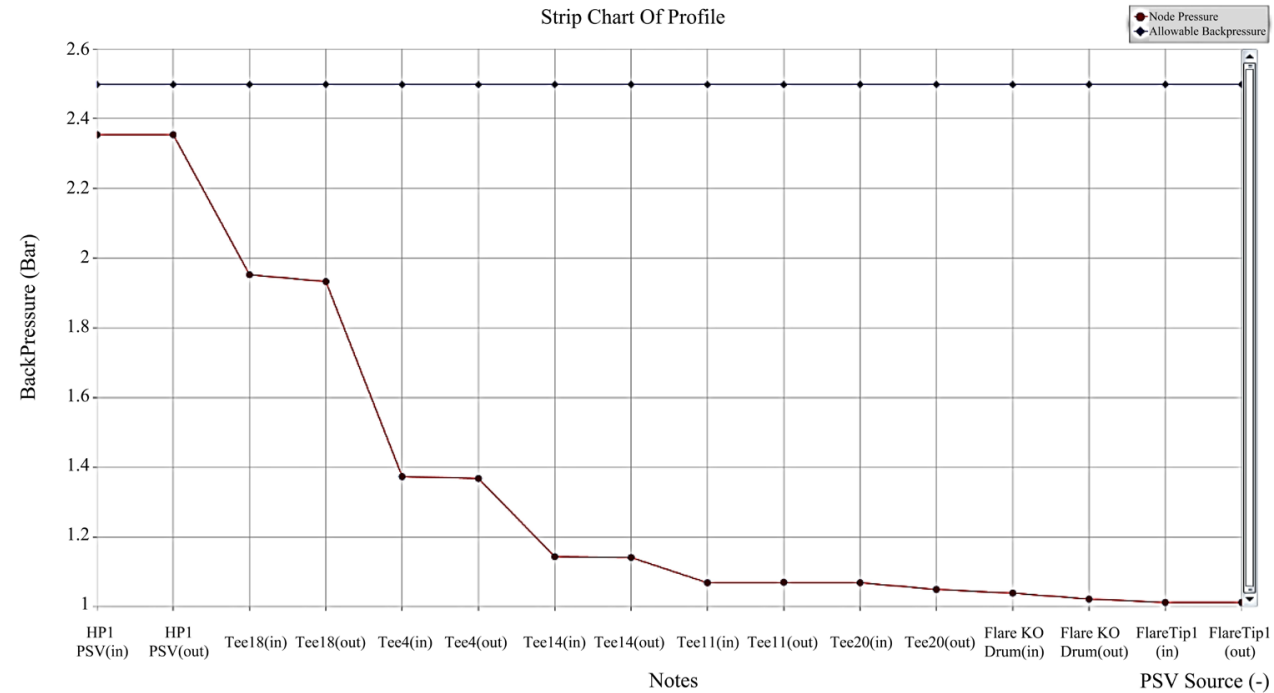

(d)

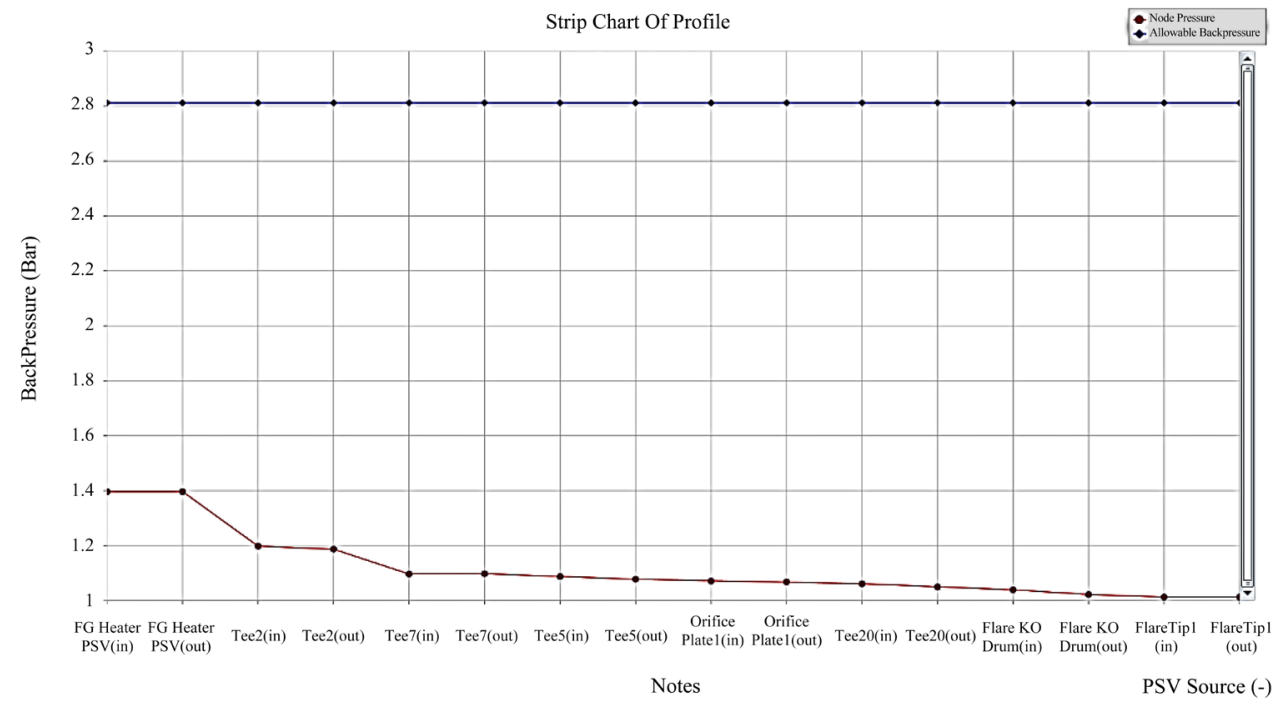

(e) 


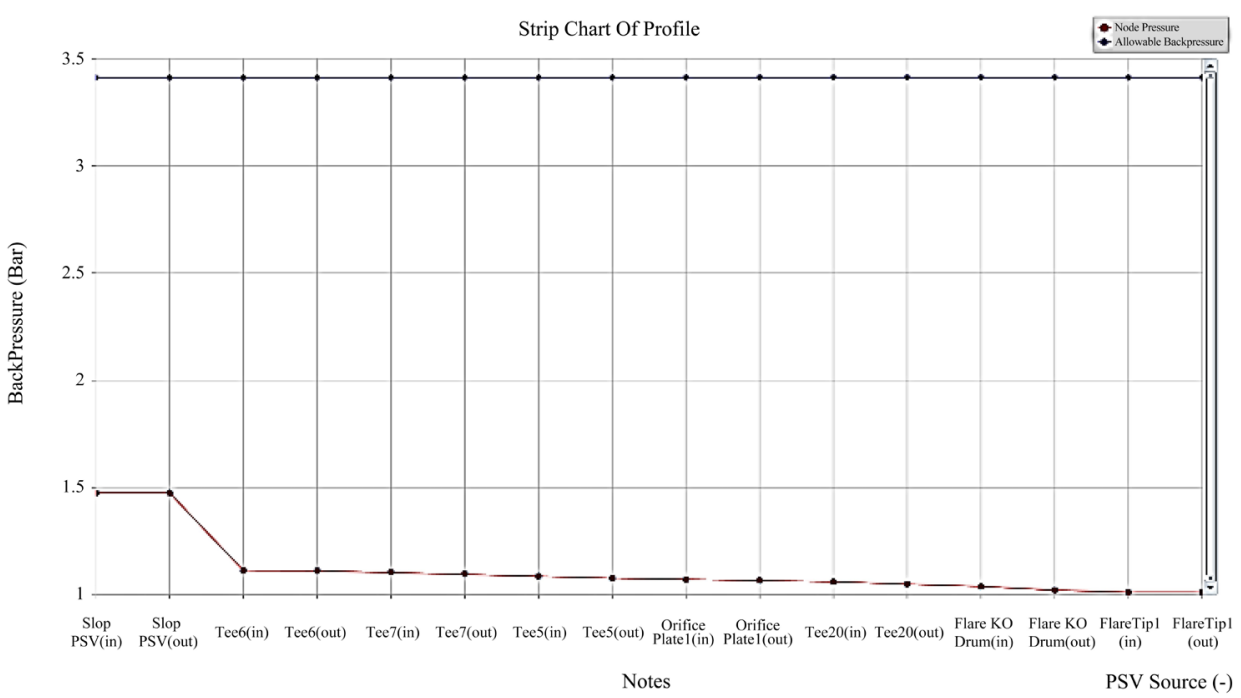

(f)

Figure 4. (a) Surge Vessel PSV versus Allowable Backpressure; (b) Extra Extra High Pressure Vessel PSV versus Allowable Backpressure; (c) Extra High Pressure Vessel PSV versus Allowable Backpressure; (d) High Pressure Vessel PSV versus Allowable Backpressure; (e) Low Pressure Vessel PSV versus Allowable Backpressure; (f) Slop Tank PSV versus Allowable Backpressure.

Low Pressure 1 Separator, Pressure Safety Valve, from Figure 4(e) has a value of 1.931 bar was recorded for the source and 1.009 bar at the outlet of the flare tip. As recorded in the preceding sources, this source also satisfied the backpressure requirements.

The Pressure Safety Valve located on the Slop Tank within the flow station satisfied the backpressure requirement in this study as shown in Figure 4(f). The source data was 1.474 bar while the data recorded at the flare tip was 1.011 bar. The results showed that all the sources/nodes had backpressures below the allowable back pressure limit. The least backpressure issued was recorded at the outlet of the flare tip and the highest value recorded at the sources. This implied that the sources as simulated satisfied this constraint.

\subsubsection{Mach No Constraint}

Mach no of 0.7 and 0.5 were used for tail pipes and header pipes respectively. High mach no is by implication high velocity which could lead to vibration in pipes, a precursor to pipe buckling and failure. The mach no criteria for each of the sources are as shown in Figures 5(a)-5(f).

Surge Vessel 1, Pressure Safety Valve had a mach no of 0.015 as shown in Figure 5(a). There was a great fluctuation in the mach no, but the highest was recorded at the knockout drum as 0.157 . These values least/highest were all below the limit defined during the simulation, thus, the source in question clearly satisfied the requirement of the mach no constraint.

From Figure 5(b), the extra extra High-Pressure Separator Pressure Safety Valve fulfiled the condition required for the mach no constraint. The source value was 0.116 and the knockout drum had a value of 0.157 at its inlet. Even at its highest value (i.e. 0.157 at knockout drum), the source data was satisfactory. 
The extra High Pressure Separator Pressure Safety Valve had some noticeable fluctuation in the mach no, but the highest point was recorded at Tee17 with a value of 0.19 still below the set point for the constraint. The source mach no was recorded as 0.143 , at the inlet of the flare tip, the value was 0.136 . As recorded with the scenarios above, this source also fulfilled the mach no constraint.

High Pressure 1 Separator Pressure Safety Valve had the highest mach no value at Tee14, least value at source, 0.093, flare tip from Figure 5(d) had a mach no of 0.136 . All stated values fell below the set mach no for this research, thus, the source was satisfactory with respect to set constraint.

Low Pressure 1 Separator Pressure Safety Valve from Figure 5(e), had a similar trend to the LP2 PSV and mach no values were approximately the same, and both fulfilled the mach no requirement for this simulation. From Figure 5(e), the source mach no was 0.087 (least), Tee14 (highest) was 0.191 and the inlet to the flare tip was 0.137 .

Slop tank Pressure Safety Valve, just like every other source defined above, was clearly satisfactory. The source as shown in Figure 5(f) had a value of 0.129 , flare tip inlet, 0.137 and the highest point on the curve was at Tee 6 with a value of 0.172 . It could therefore be stated that mach number requirement was satisfied as all nodes had mach number below 0.2 .

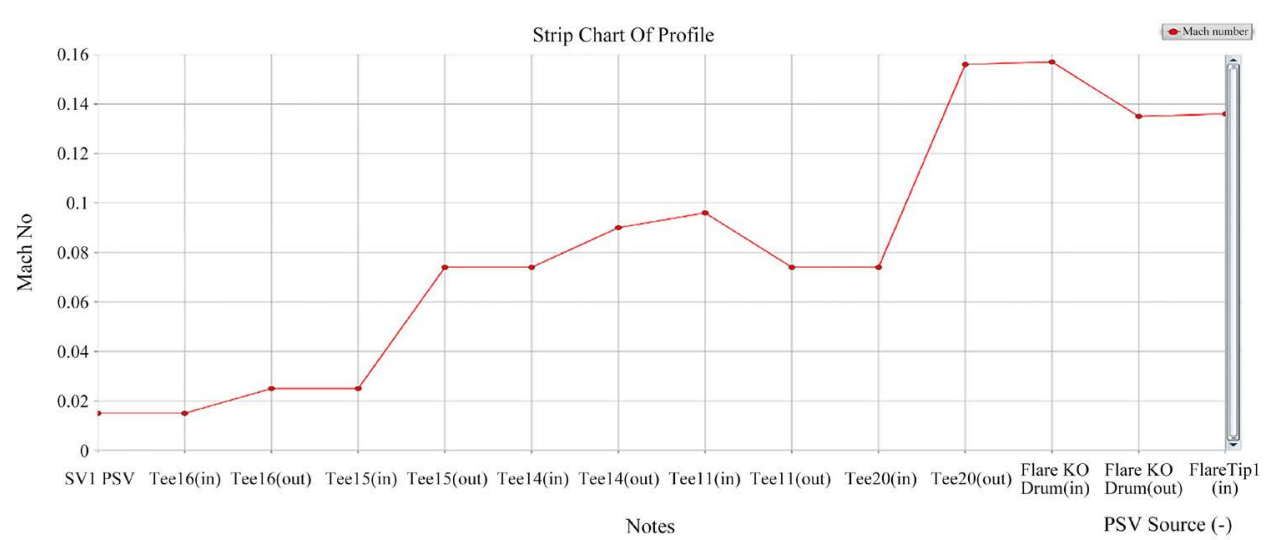

(a)

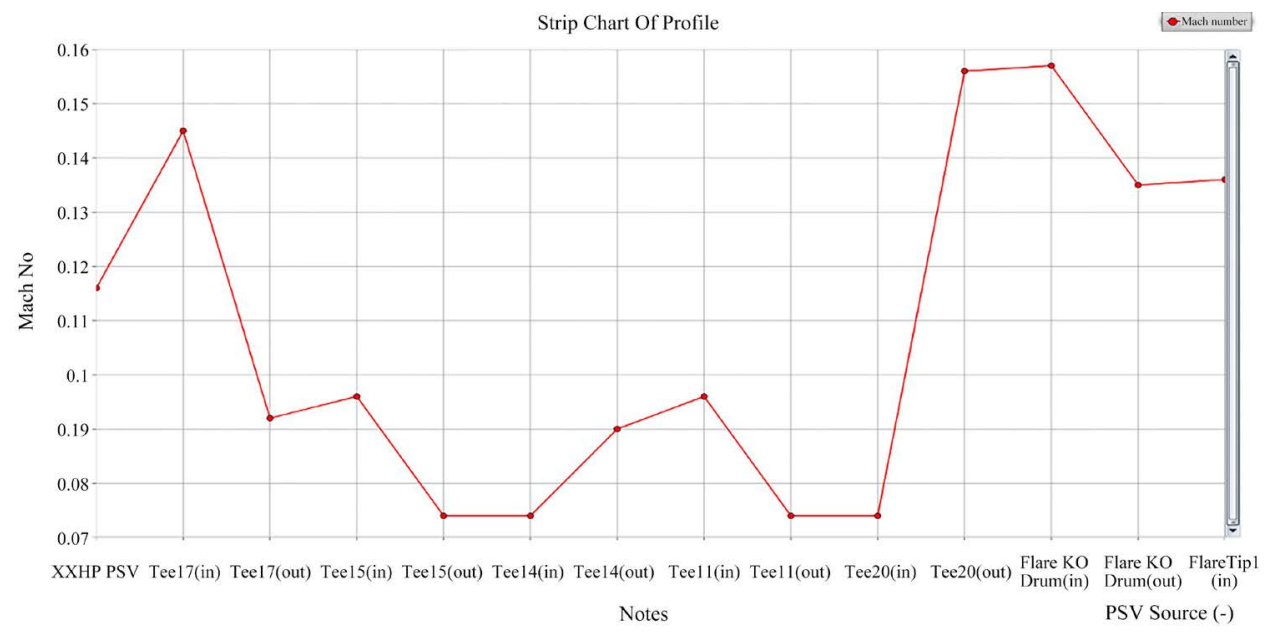

(b) 


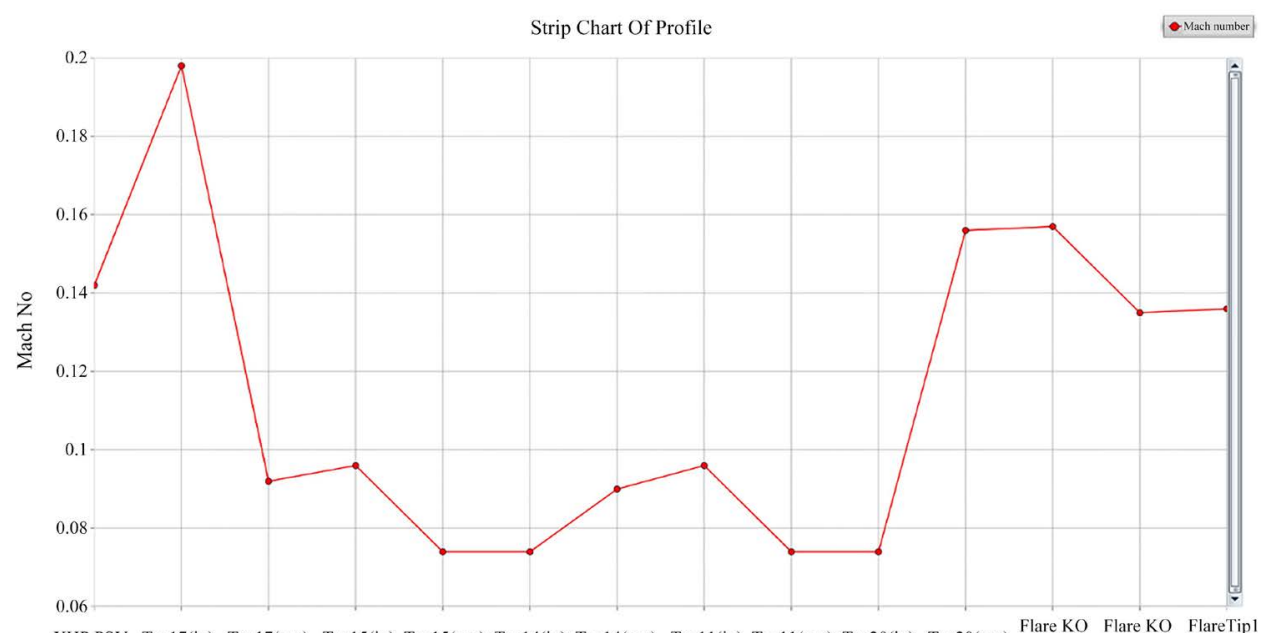
XHP PSV Tee17(in) Tee17(out) Tee15(in) Tee15(out) Tee14(in) Tee14(out) Tee11(in) Tee11(out) Tee20(in) Tee20(out) $\begin{gathered}\text { Flare KO } \\ \text { Drum(in) }\end{gathered}$ Dlare KO Fum(out) (in)

Notes

PSV Source (-)

(c)

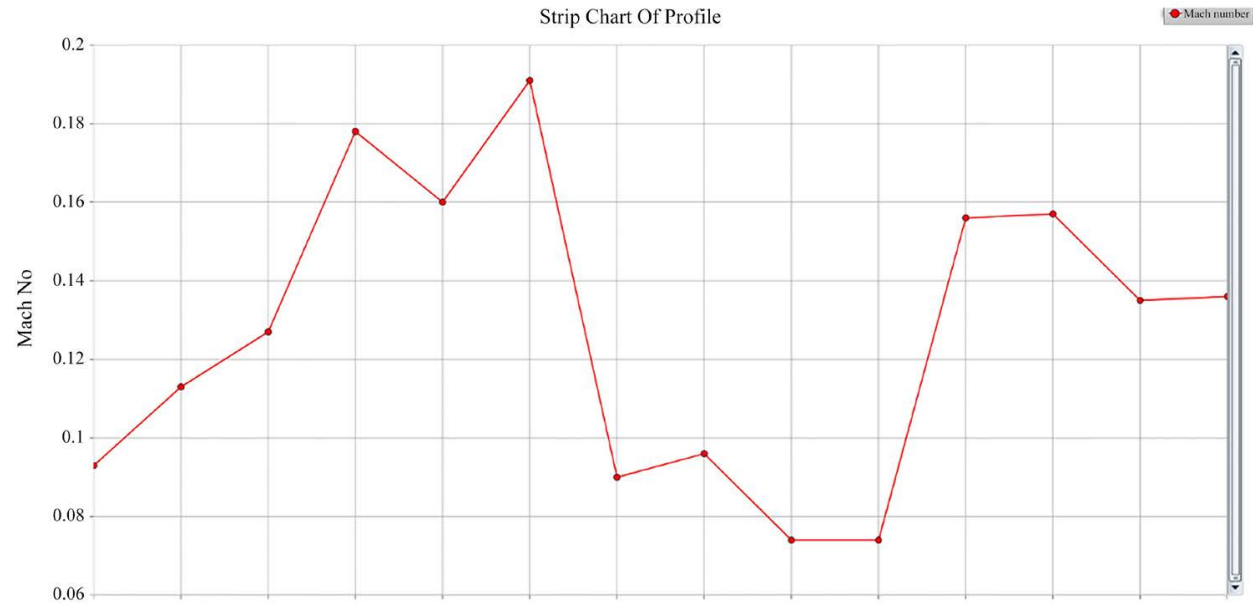
HPI PSV Tee18(in) Teel8(out) Tee4(in) Tee4(out) Teel4(in) Teel4(out) Teel1(in) Teel1(out) Tee20(in) Tee20(out) $\begin{aligned} & \text { Flare KO Frum(in) } \\ & \text { Dlure KO (out) FlareTipl }\end{aligned}$ Notes

PSV Source (-)

(d)

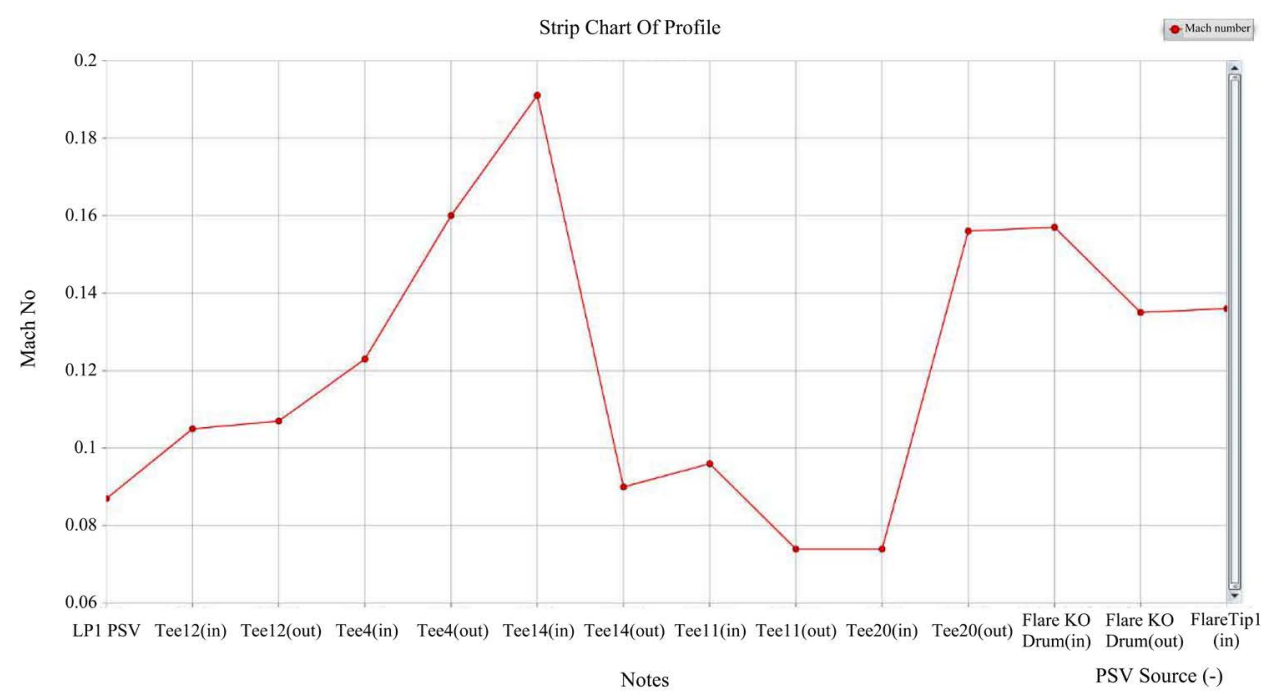

(e) 


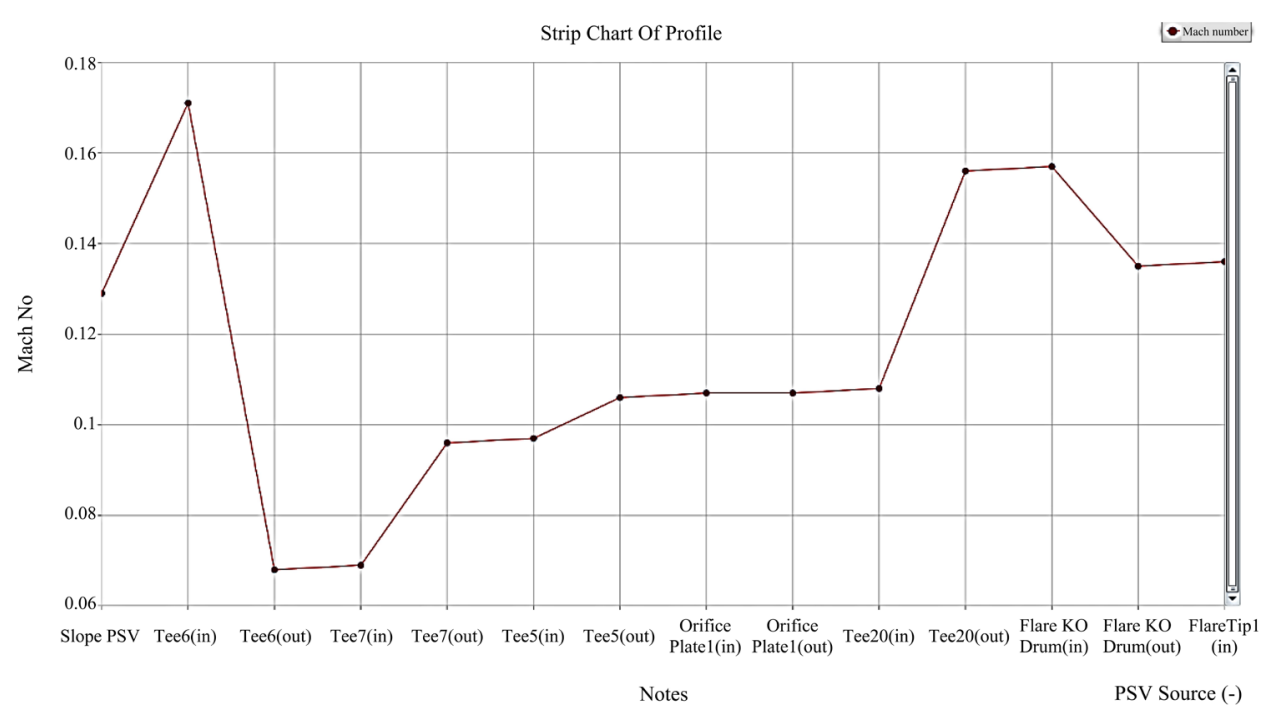

(f)

Figure 5. (a) Surge vessel PSV versus mach number; (b) Extra Extra High Pressure Vessel PSV versus Mach Number; (c) Extra High Pressure Vessel PSV versus Mach Number; (d) High Pressure Vessel PSV versus Mach Number; (e) Low Pressure Vessel PSV versus Mach Number; (f) Slop Tank PSV versus Mach Number.

\subsubsection{Noise Constraint}

As fluid passed through the PSV (tail and header pipes), significant noise was produced and transmitted along the tail and header pipes. During intermittent emergency relief scenario, the noise was limited to $115 \mathrm{~dB}$ and during continuous relief scenario, it was limited to $85 \mathrm{~dB}$.

The noise constraint was required to be less than or equal to $80 \mathrm{~dB}$ upstream and $115 \mathrm{~dB}$ downstream the sources. The individual sources plot with respect to the noise criteria is as shown in Figures 6(a)-6(f). In Figure 6(a), the least noise level was recorded at the source as $0.078 \mathrm{~dB}$ while the highest noise level was recorded at the inlet to the flare tip as $48.269 \mathrm{~dB}$. The noise set point was not exceeded thus, the source met the criteria defined for this simulation.

The PSV source on this separator has a noise level of $42.406 \mathrm{~dB}$ as shown in Figure 6(b). The knockout drum outlet had the highest noise level as $48.310 \mathrm{~dB}$. Both noise levels fell below the noise limit, thus, the source data was satisfactory with respect to set constraint.

xHP source as shown in Figure 6(c) had $45.228 \mathrm{~dB}$ as the source noise level and $48.136 \mathrm{~dB}$ for the knock out drum respectively. The noise level fell within tolerance limit from the defined constraint at the beginning of this studies.

Tee14 had the highest noise level from Figure 6(d), its value was $49.309 \mathrm{~dB}$, the inlet of the flare tip had $48.18 \mathrm{~dB}$ and the source had $32.116 \mathrm{~dB}$ respectively. Comparing the stated values with the set point for noise constraint, it is quite clear that the constraint was satisfied.

Noise level deduced from the LP1 PSV plot shown in Figure 6(e) indicated that the sources had no noise concerns. The highest noise level was noticed at Tee14 with a value of $49.352 \mathrm{~dB}$, followed by $48.267 \mathrm{~dB}$ at the inlet to the flare tip. 
The source had a value of $20.481 \mathrm{~dB}$, this was adequately satisfactory in terms of meeting the set constraint.

Slop tank PSV indicated a very low noise level at its source, $0.223 \mathrm{~dB}$ and $48.341 \mathrm{~dB}$ at the inlet to the flare tip. In Figure 6(f), there was no noise concern as well as the set constraint value $(80 \mathrm{~dB} / 115 \mathrm{~dB}$ for inlet and outlet) was not violated. From the results, noise was not a concern for the sources as they were all below the set points, $80 \mathrm{~dB} / 115 \mathrm{~dB}$ for inlet and outlet as was set as the limit for the noise in the simulation. Thus, all sources were accepted at the level of noise issues.

\subsubsection{Rho V² Constraint}

The momentum defined as $\mathrm{RhoV}^{2}$ was expected to be within $6000 \mathrm{~kg} / \mathrm{m} / \mathrm{s}^{2}$. This was vital in satisfying the momentum balance in the simulation.

The Rho $\mathrm{V}^{2}$ to be limited to prevent turbulence-induced vibration of flare piping. As per clause 6.5.1 of NORSOK Standard P-001 (Process Design), all flare lines shall be designed to keep the rho $\mathrm{v}^{2}<200,000 \mathrm{~kg} / \mathrm{m} / \mathrm{s}^{2}$ criteria, in this work, the criteria were made more stringent by pegging it at $6000 \mathrm{~kg} / \mathrm{m} / \mathrm{s}^{2}$.

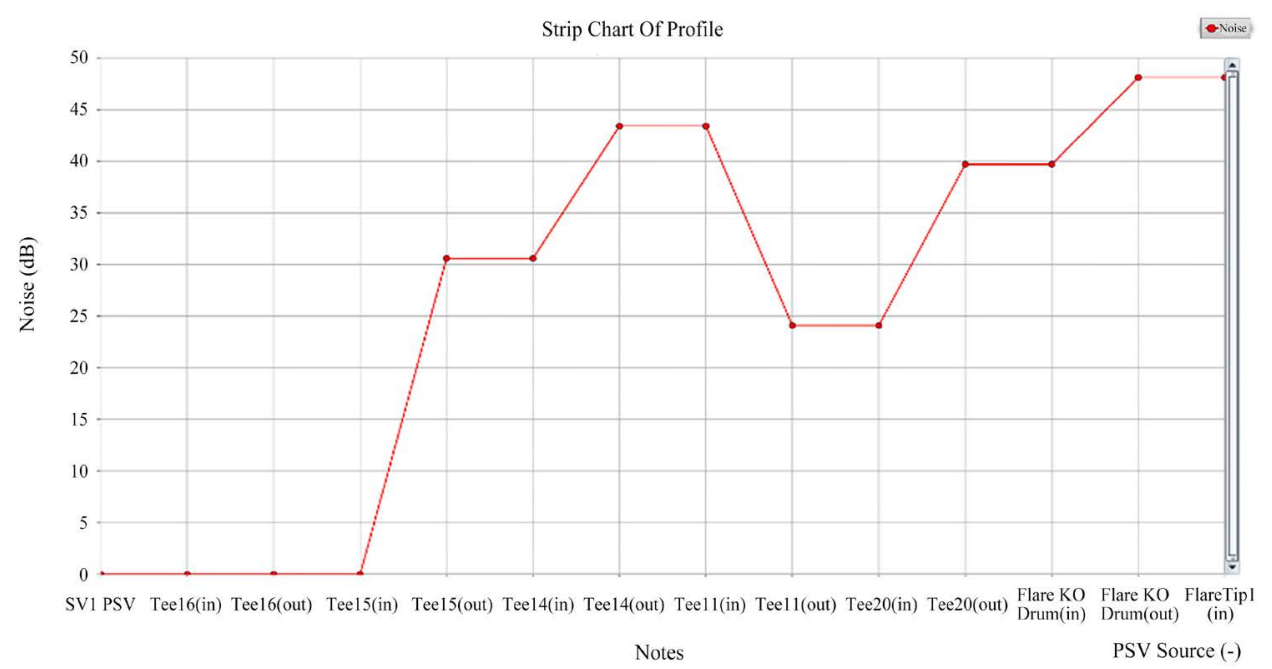

(a)

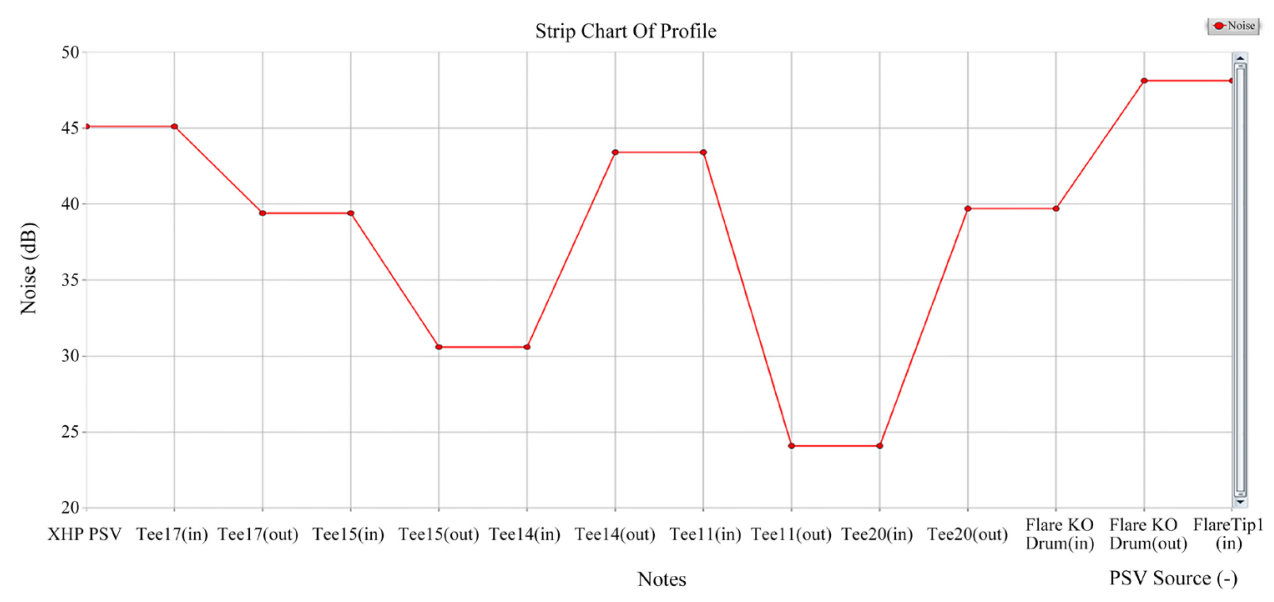

(b) 


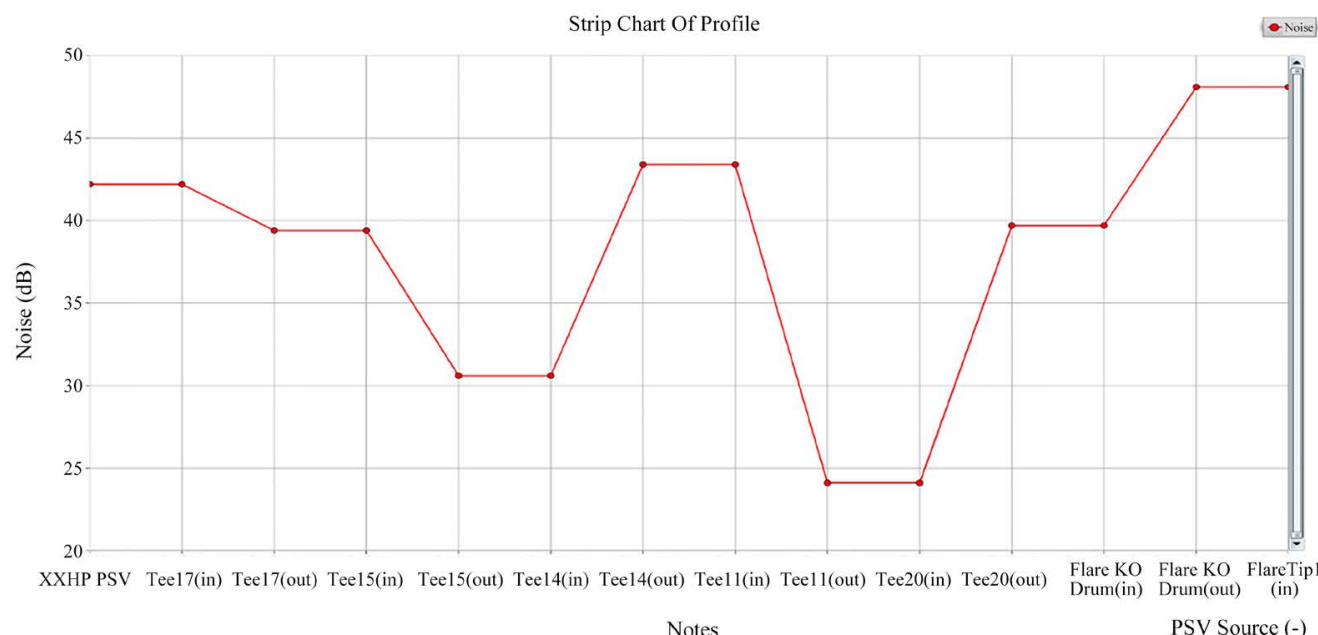

(c)

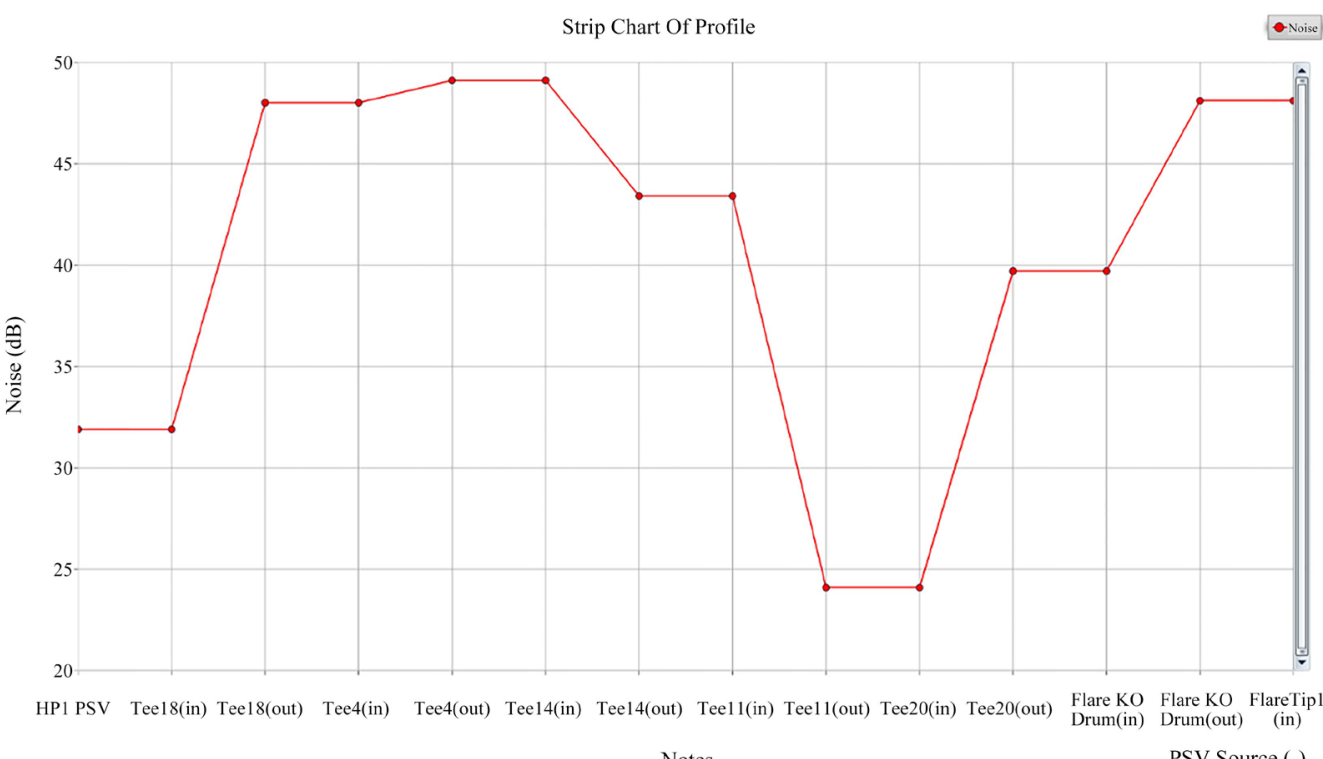

(d)

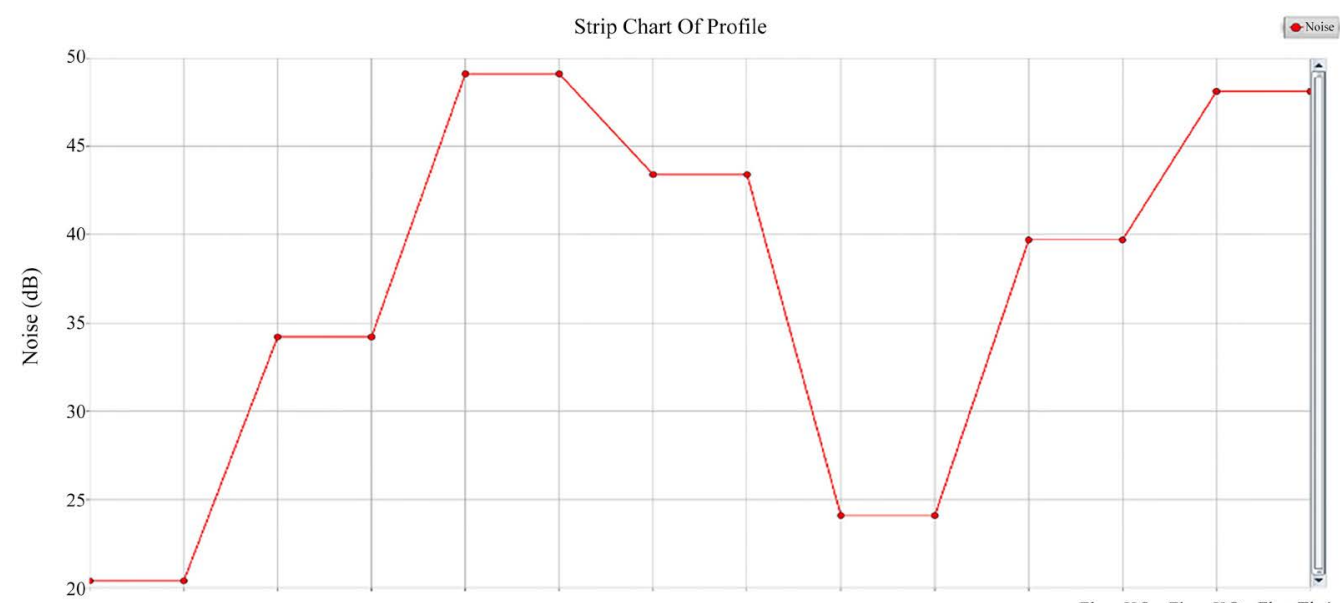

LP1 PSV Tee12(in) Tee12(out) Tee4(in) Tee4(out) Tee14(in) Tee14(out) Tee11(in) Tee11(out) Tee20(in) Tee20(out) $\begin{aligned} & \text { Flare KO } \\ & \text { Drum(in) }\end{aligned} \begin{aligned} & \text { Flare KO } \\ & \text { Drum(out) }\end{aligned} \begin{aligned} & \text { FlareTipl } \\ & \text { (in) }\end{aligned}$ Notes

PSV Source (-)

(e) 


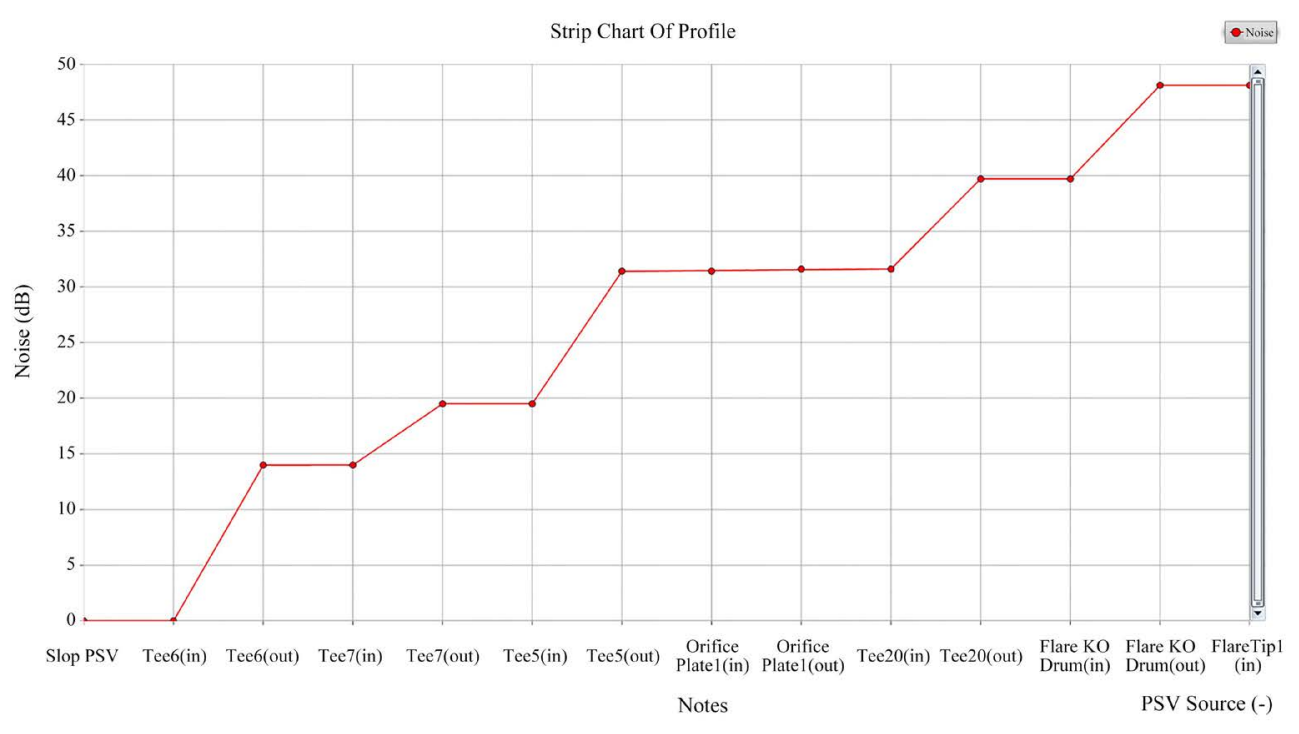

(f)

Figure 6. (a) Surge vessel PSV versus noise; (b) Extra Extra High Pressure PSV versus Noise; (c) Extra High Pressure Vessel PSV versus Noise; (d) High Pressure Vessel PSV versus Noise; (e) Low Pressure Vessel PSV versus Noise; (f) Slop Tank PSV versus Noise.

Figure 7 (a) indicates that the source $\mathrm{rhoV}^{2}$ was $30.796 \mathrm{~kg} / \mathrm{m} / \mathrm{s}^{2}$, at the flare tip inlet $45.991 \mathrm{~kg} / \mathrm{m} / \mathrm{s}^{2}$ and the highest value recorded at the flare knock out drum as $3135.701 \mathrm{~kg} / \mathrm{m} / \mathrm{s}^{2}$. There was no violation of the set constraint as deduced from the plot above, thus, SV1 separator PSV had satisfactory values in terms of momentum constraint.

Extra extra High-Pressure Separator Pressure Safety Valve also satisfied rho $\mathrm{V}^{2}$ concerns as the values deduced from Figure 7(b) fell within the limit of the constraint. The source had $2406.272 \mathrm{~kg} / \mathrm{m} / \mathrm{s}^{2}$ while the knock out drum had $3144.329 \mathrm{~kg} / \mathrm{m} / \mathrm{s}^{2}$. Comparing with the set point of $6000 \mathrm{~kg} / \mathrm{m} / \mathrm{s}^{2}$, the source was adequately satisfactory.

From Figure $7(\mathrm{c})$, the peak of the plot was at Tee17 with a value of 5783.590 $\mathrm{kg} / \mathrm{m} / \mathrm{s}^{2}$ at Tee17. The source values were $4177.23 \mathrm{~kg} / \mathrm{m} / \mathrm{s}^{2}$ and knockout drum $3135.267 \mathrm{~kg} / \mathrm{m} / \mathrm{s}^{2}$ respectively. These values were below the momentum set point, thus the source satisfied the constraint.

Momentum constraint on the HP1 separator PSV is depicted in Figure 7(d). Momentum at the source was $2447.024 \mathrm{~kg} / \mathrm{m} / \mathrm{s}^{2}$, the knock out drum was $3134.430 \mathrm{~kg} / \mathrm{m} / \mathrm{s}^{2}$ and the peak point was at Tee4 having a value of 5182.177 $\mathrm{kg} / \mathrm{m} / \mathrm{s}^{2}$ respectively. These values fell within tolerance limit for the constraint under consideration.

$\mathrm{RhoV}^{2}$ constraint for LP1 Separator PSV was deemed satisfied from the data obtained from Figure $7(\mathrm{e})$. The highest point was at Tee14 with a value of $4928.864 \mathrm{~kg} / \mathrm{m} / \mathrm{s}^{2}$, which was far less than the set point. The source was at $1679.242 \mathrm{~kg} / \mathrm{m} / \mathrm{s}^{2}$ and knockout drum at $3131.478 \mathrm{~kg} / \mathrm{m} / \mathrm{s}^{2}$.

Slop tank PSV like every other source discussed have values deducted from Figure 7(f) fall within acceptable values for the constraint considered. From the plot, it could be deduced that, the source was $3463.604 \mathrm{~kg} / \mathrm{m} / \mathrm{s}^{2}$, knock out drum 
was $3137.990 \mathrm{~kg} / \mathrm{m} / \mathrm{s}^{2}$ and the peak point at Tee6 was $4596.739 \mathrm{~kg} / \mathrm{m} / \mathrm{s}^{2}$ respectively. As indicated, all sources operated below the set point for momentum, which was set at $6000 \mathrm{~kg} / \mathrm{m} / \mathrm{s}^{2}$ thus, acceptably satisfied the constraint.

\subsection{Combined Flare Network Results}

\subsubsection{Combined Flare Systems for Onage Refinery and Egam Flow Station before Debottlenecking}

After individual simulation of the refinery and flow station respectively, the flare systems were comingled but without debottlenecking. Figure 8 shows a plot of the tail and header pipe diameters that satisfied the constraints used for the simulation process. The simulation PFD is as shown in appendix attached.

\subsubsection{Combined Flare Systems for Onage Refinery and Egam Flow Station after Debottlenecking}

Finally, the comingled system was debottlenecked to obtain the pinch point, which was the optimum pipe sizes that satisfied all the constraints (mach no, noise, rho $\mathrm{V}^{2}$ and backpressure) and offered an economic solution with a reduced environmental negative impact. The results was as shown in Figure 9.

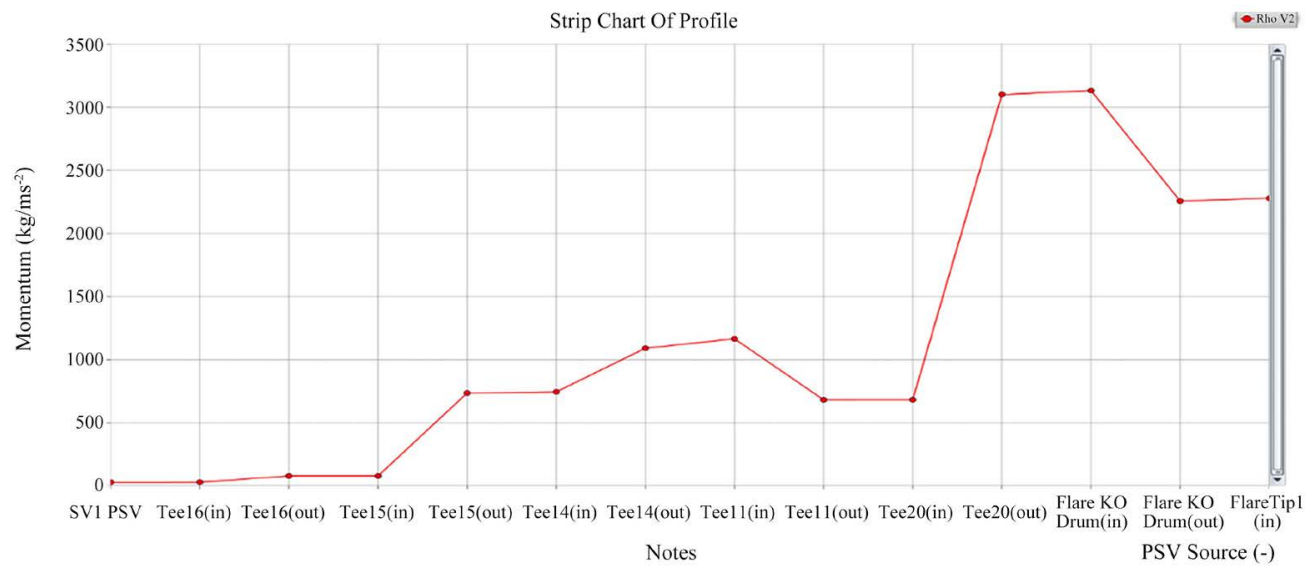

(a)

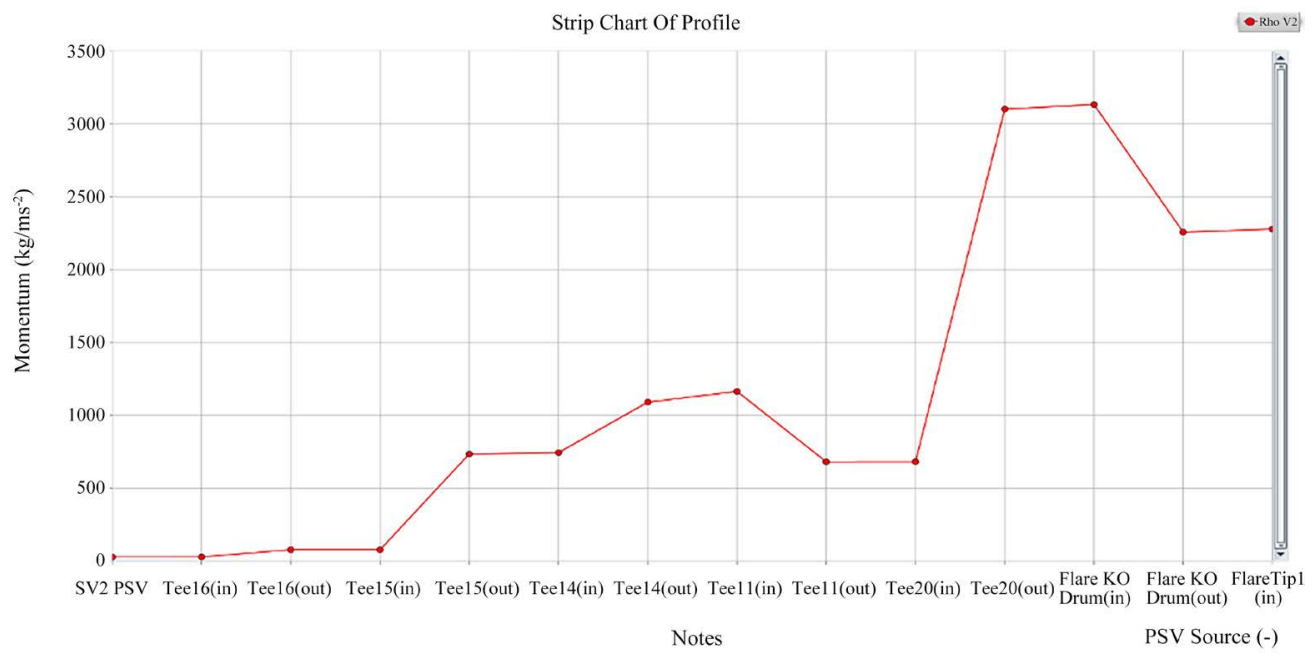

(b) 


\section{L. Pemii et al.}

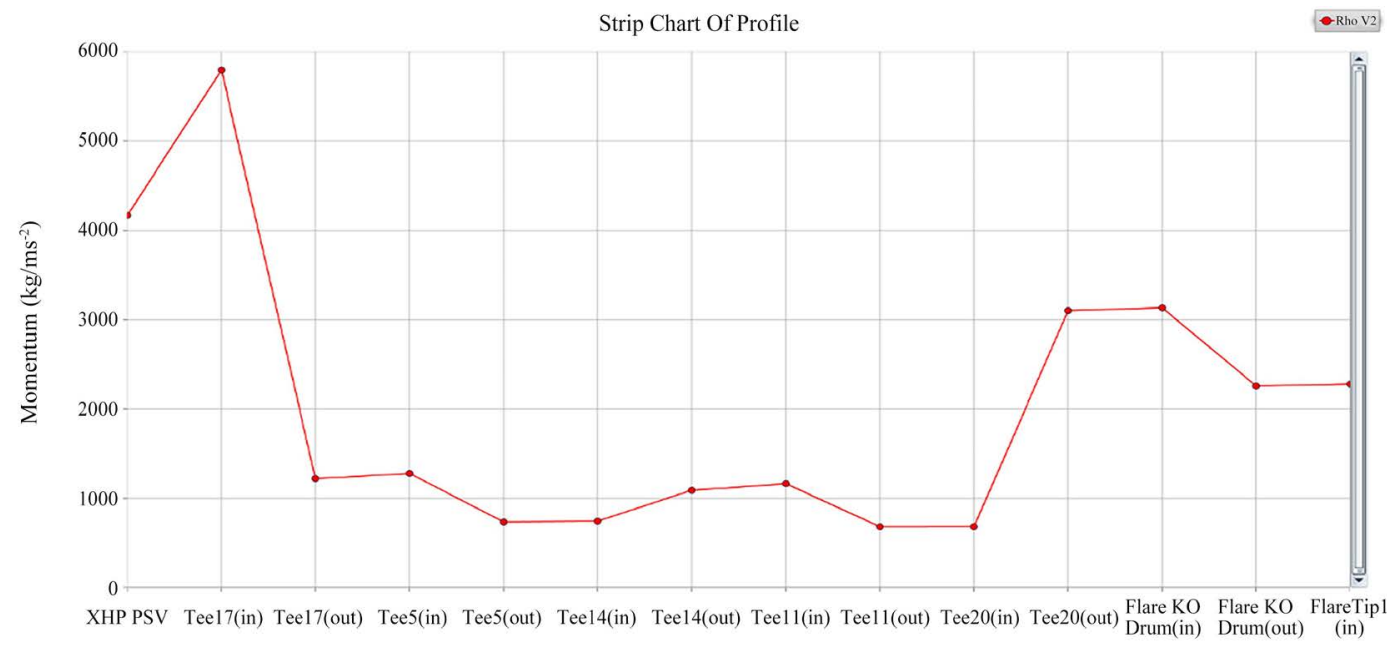

Notes

PSV Source (-)

(c)

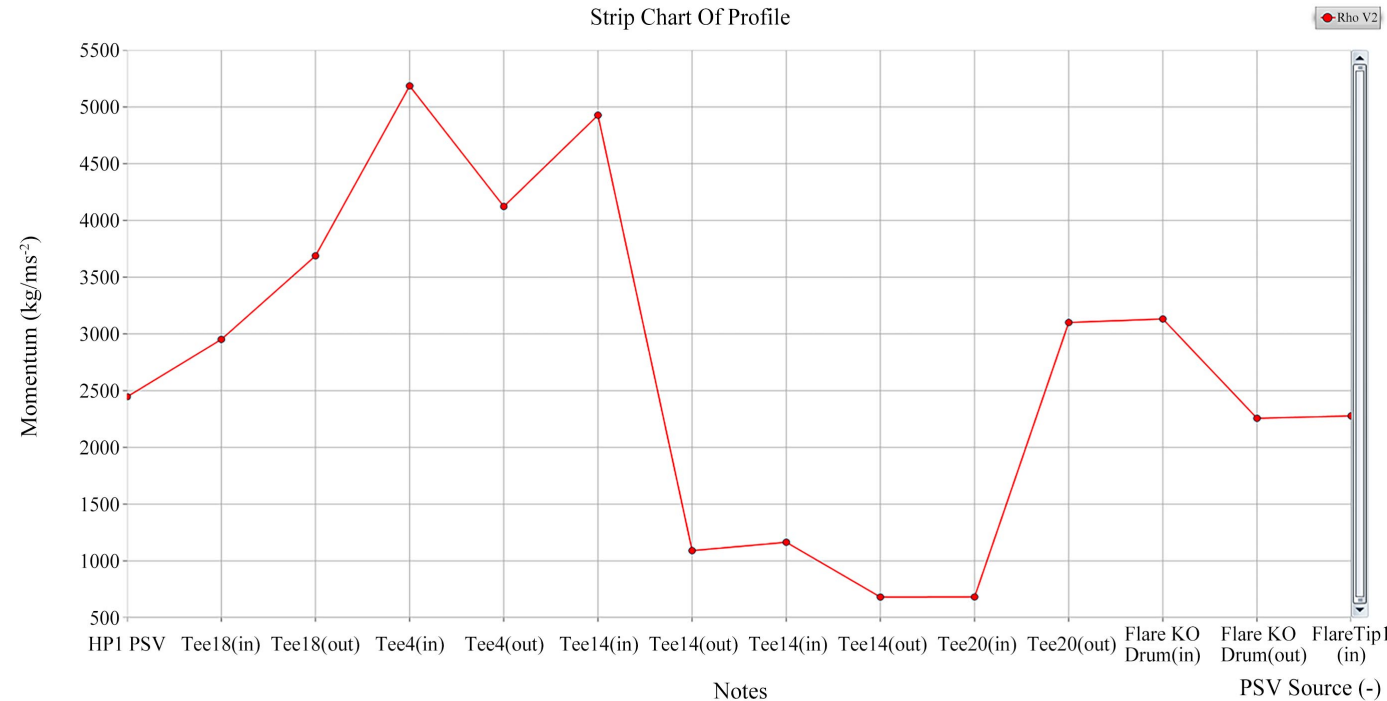

(d)

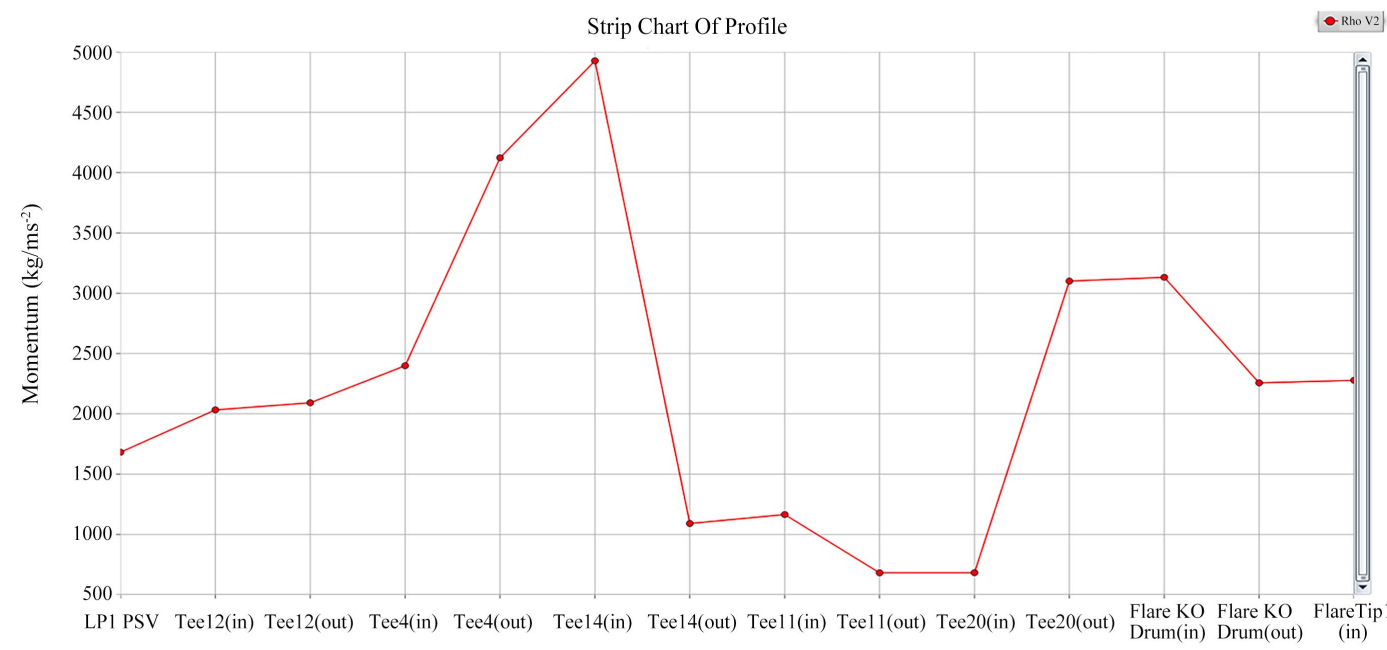

Notes

PSV Source (-)

(e) 


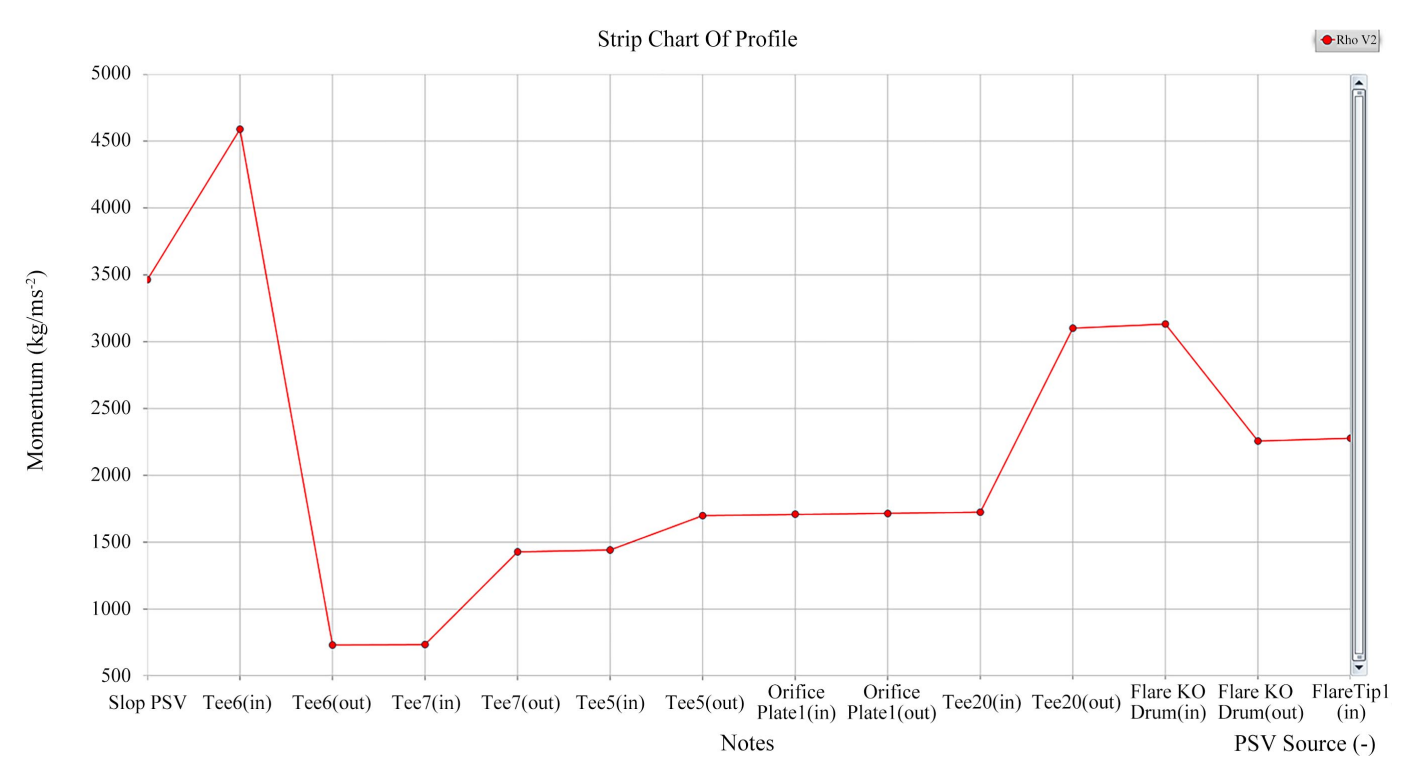

(f)

Figure 7. (a) Surge vessel PSV versus momentum; (b) Extra Extra High Pressure Vessel PSV versus Momentum; (c) Extra High Pressure Vessel PSV versus Momentum; (d) High Pressure Vessel PSV versus Momentum; (e) Low Pressure Vessel PSV versus Momentum; (f) Slop Tank PSV versus Momentum.

\subsection{Comparison of the Debottlenecked and None Debottlenecked Cases}

A summary of the debottlenecked and none debottlenecked cases is shown in Figure 3. It compares the resultant pipe diameters for the systems. Result indicates that the debottlenecked (optimized) flare network had better pipe sizes than the normal non-debottlenecked system,

\section{Conclusion}

The developed models for this work were resolved using Aspen Flare Analyzer which produced two independent flare networks for Egam flow station and Onage refinery. The two networks were later combined into a single flare network and analyzed using four (4) constraints. The constraint which formed the basis for the analysis is assigned limits obtained from Aspen Flare Analyzer data base. The constraints were backpressure requirement, this was set with respect to individual sources (PSVs), Mach number set at 0.7 for tail pipes and 0.5 for header pipes, Noise set at $80 \mathrm{~dB}$ for inlet and $115 \mathrm{~dB}$ for outlet of the sources and RhoV ${ }^{2}$ constraint which was set at $6000 \mathrm{~kg} / \mathrm{m} / \mathrm{s}^{2}$ respectively. Application of Pinch Analysis to the combined flare network yielded reduced tail and header pipe diameters. These pipe diameters when compared with those of the system before debottlenecking and those of the individual networks before comingling offered great advantage as the respective pipe sizes were smaller for the debottlenecked system than all other systems. A $20 \%$ difference in pipes sizes was recorded which translated into a significant cost difference as the internal diameter and thickness of a pipe segment determine to a reasonable extent the cost of the pipe. 


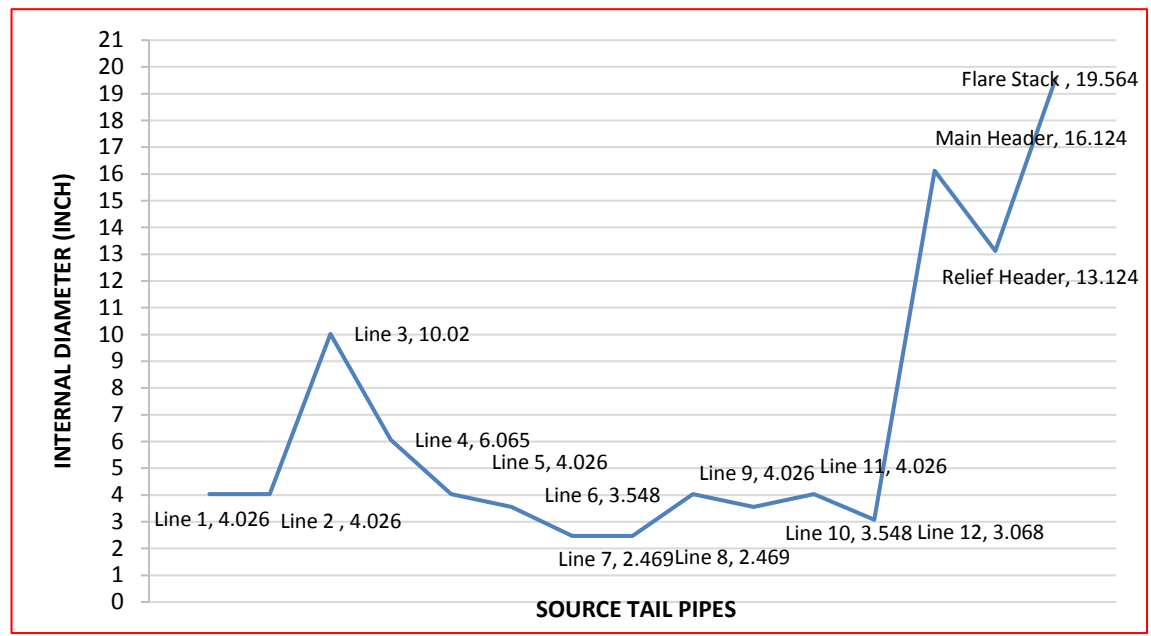

Figure 8. Comingled flare simulation result before debottlenecking.

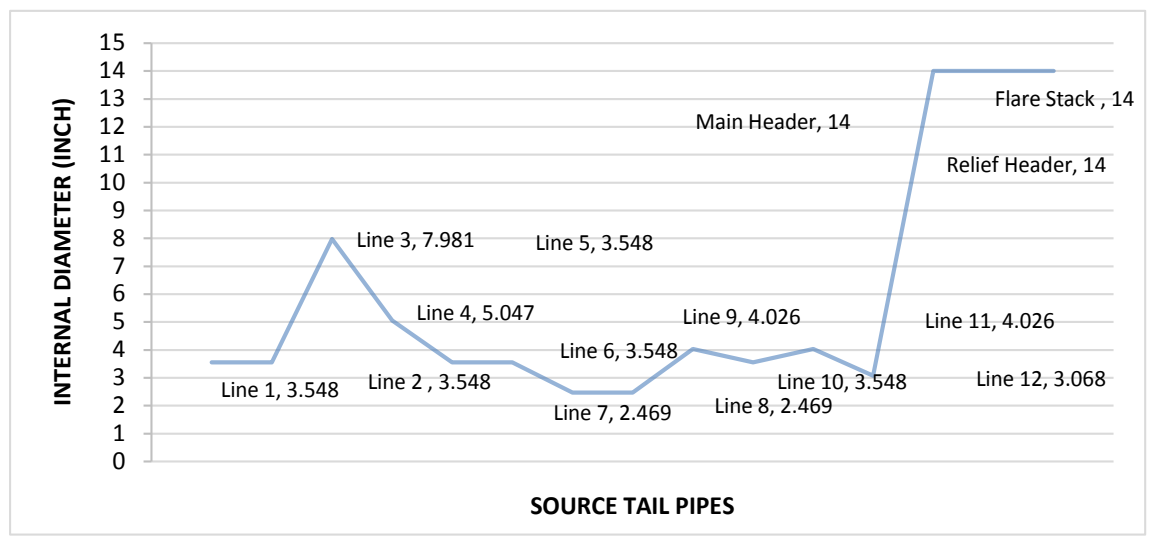

Figure 9. Comingled flare simulation result after debottlenecking (Pinch Point). See attached appendix for the simulation PFD.

This research showed that the concept of Pinch Analysis could be applied in optimizing different flare networks. Comingling flare networks of facilities in close proximity will yield a better system with both economic and environmental advantages by reduction of emission of greenhouse gases/reduction in global warming. While efforts are in top gear to end gas flaring in Nigeria, companies that have multiple facilities in close proximities should consider integrating their gas flare networks rather than having individual gas flare systems that will have more negative cost implications.

\section{Conflicts of Interest}

The authors declare no conflicts of interest regarding the publication of this paper.

\section{References}

[1] Eman, A.E. (2015) Gas Flaring in Industry: An Overview. Petroleum \& Coal, 57, 532-555. 
[2] Enayati, S.M. and Anajafi, E. (2015) Design Criteria and Simulation of Flare Gas Recovery System. International Conference on Chemical, Food and Environmental Engineering, Dubai, 11-12 January 2015, 35-39.

[3] Federal Ministry of Energy of Nigeria, Energy Commission of Nigeria (2012) Renewable Energy Master Plan (Revised Draft Edition).

[4] Department of Petroleum Resources, Ministry of Petroleum, Federal Government of Nigeria. https://www.dpr.gov.ng/\#

[5] Linnhoff, B. (1994) Use Pinch Analysis to Knock down Capital Costs and Emission. Chemical Engineering Progress, 90, 32-57.

[6] Nursen, A. and Zehra, O. (2017) Debottlenecking and Retrofitting by Pinch Analysis in a Chemical Plant. American Journal of Energy Engineering, 5, 39-49. https://doi.org/10.11648/j.ajee.20170505.13

[7] Ajao, K.R. and Akande, H.F. (2009) Energy Integration of Crude Distillation Unit Using Pinch Analysis. Researcher, 1, 54-66.

[8] Badr, A., Jirí, J.K. and Simon, P. (2001) Heat Integration Retrofit Analysis of a Heat Exchanger Network of a Fluid Catalytic Cracking Plant. Applied Thermal Engineering, 21, 1449-1487. https://doi.org/10.1016/S1359-4311(01)00028-X

[9] Auta, M., Ahmad, A.S. and Akande, H.F. (2012) Comparative Studies of Traditional (Non-Energy Integration) and Energy Integration of Catalytic Reforming Unit Using Pinch Analysis. Nigeria Journal of Technological Development, 9, 1-10.

[10] Anchal, S. and Nitesh (2018) Flare Radiation Mitigation Analysis of Onshore Oil \& Gas Production \& Refining Facility for a Low Cost De-Bottlenecking Using Computer Aided Techniques. International Journal of Scientific \& Engineering Research, 9, 975-982.

[11] Remi-Erempagamo, M.T. (2012) Thermo-Hydraulic Modeling of Flow in Flare Systems. Faculty of Science and Technology, University of Stavanger, Stavanger.

[12] Shenoy, U.V. (2011) Unified Targeting Algorithm for Diverse Process Integration Problems of Resource Conservation Networks. Chemical Engineering Research and Design, 89, 2686-2705. https://doi.org/10.1016/j.cherd.2011.04.021

[13] Tan, R.R. and Foo, D.C.Y. (2007) Pinch Analysis Approach to Carbon-Constrained Energy Sector Planning. Energy, 32, 1422-1429. https://doi.org/10.1016/j.energy.2006.09.018

[14] Venkatesh, G. (2019) Pinch Analysis, as a Technique for Optimizing Resource Utilization and Promoting Environmental Sustainability: A Review of Recent Case Studies from the Developing World and Transition Economies. Resources Environment and Information Engineering, 1, 1-17. https://doi.org/10.25082/REIE.2019.01.001

[15] Tan, R.R., Abdul, A.M.K., Ng, D.K.S., Foo, D.C.Y. and Lam, H.L. (2015) Pinch Analysis Based Approach to Safety Risk Management in the Process Industries. Chemical Engineering Transactions, 45, 133-138.

[16] http://gasflaretracker.ng/

[17] Weam and Company Nigeria Limited (2018) Aspen Flare Analyzer Training Manual. 
Appendix: Combined Refinery and Flow Station Simulation PFD

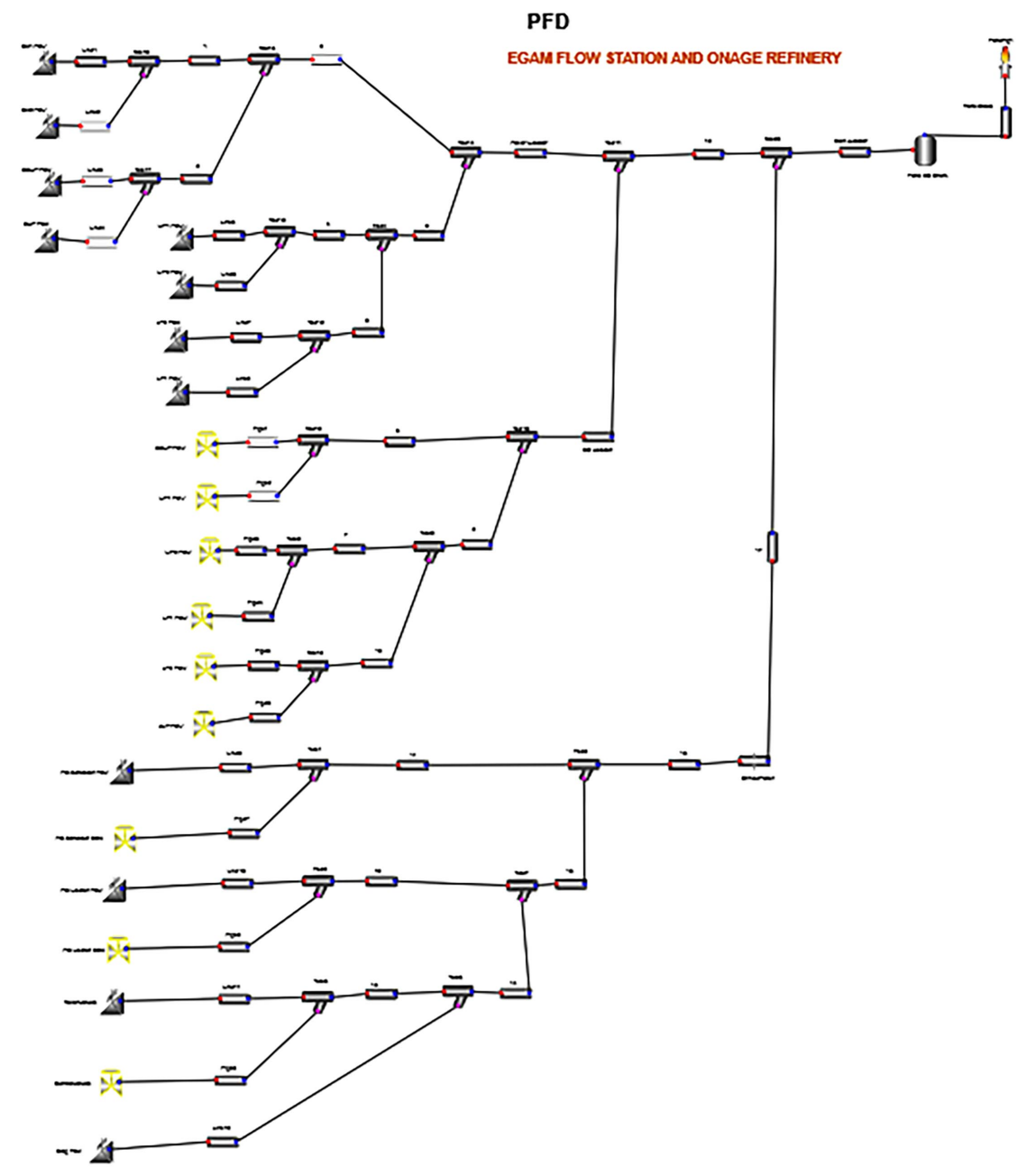

